\title{
Gamma Irradiation and Oxidative Degradation of a Silica-Filled Silicone Elastomer
}

\author{
Andrea Labouriau* ${ }^{\mathrm{a}}$, Carl Cady $^{\mathrm{b}}$, John Gill $^{\mathrm{a}}$, Jamie Stull ${ }^{\mathrm{b}}$, Denisse Ortiz-Acosta \\ ${ }^{a}$, Kevin Henderson ${ }^{b}$, Vaughn Hartung ${ }^{b}$, Adam Quintana ${ }^{c}$, and Mathew Celina ${ }^{c}$ \\ ${ }^{a}$ Chemical Diagnostic and Engineering, ${ }^{\mathrm{b}}$ Division of Materials Science and \\ Technology, Los Alamos National Laboratory, Los Alamos, New Mexico, 87545 \\ ${ }^{\mathrm{c}}$ Sandia National Laboratories, Materials Characterization and Performance Dept. \\ 1819, Albuquerque, New Mexico, 87185
}

\begin{abstract}
The radiation oxidative degradation of a commonly used silica-filled silicone elastomer DC745 was investigated by a series of experimental techniques. This elastomer is known to be chemically and thermally stable, but insufficient data exist on its radiation resistance. In the present work, gamma doses up to $200 \mathrm{kGy}$ were applied under air at room temperature and $1 \mathrm{~Gy} / \mathrm{s}$. Chemical changes due to radiation were investigated by NMR, FT-IR, resonance Raman, and mass spectroscopy. DSC and TGA experiments probed thermal transitions and thermal stability changes with exposure dose. SEM probed variations on the surface of the elastomer, and changes in the polymer network were investigated using solvent swelling methods. Electron paramagnetic resonance (EPR) was employed to detect and identify free radicals. Uniaxial compression load tests at variable temperatures were performed to assess changes in the material's mechanical response as a function of radiation dose. Results demonstrate that, with increasing exposure, DC745 undergoes changes in chemistry that lead to an increase in thermal stability and cross-link density, formation of free radical species, decrease in heat of fusion and increase in stiffness at low temperatures. Taken together, these results indicate that oxidative crosslinking is the dominant radiolysis mechanism that occurs when this material is exposed to gamma irradiation in air.
\end{abstract}

Keywords: PDMS, irradiation, oxidative degradation.

Corresponding author: A. Labouriau (andrea@lanl.gov), phone: 1-505-667-7216.

\section{LA-UR-15-21100}




\section{Introduction.}

Siloxane polymers are used in numerous applications and are thus subjected to various environmental conditions that may adversely impact their performance and stability. In particular, it is important to understand changes in structure-property relationships that are triggered by exposure to harsh environments. For instance, ionizing radiation can greatly alter the molecular structure and thereby the macroscopic properties of polymers through 'radiation chemistry' mechanisms like chain scission, cross-linking and oxidation. ${ }^{1,2}$ Consequently, understanding the molecular origin of these chemical and structural changes is important in order to predict the material's lifetime. Ideally, sensitive experimental methods would provide the means to fully determine the radiolysis mechanisms that trigger damage and limit long-term performance. However, due to the low sensitivity of many experimental techniques, polymers are usually exposed to high gamma doses in order to create significant degradation in the material. This approach certainly allows for easier experimental detection of radiolysis induced damage, but it may also lead to promoting mechanisms that do not occur under lower dose and dose rate conditions.

In this work, we were interested in exposing a commercially available crosslinked and silica filled elastomer DC745 to moderate doses of gamma irradiation. Radiolysis in this material was previously investigated for samples exposed to doses up to $250 \mathrm{kGy}$ under nitrogen atmosphere. ${ }^{3}$ The authors employed NMR techniques to demonstrate that gamma exposure decreased polymer chain segmental dynamics, which was accompanied by a bimodal distribution of residual dipolar couplings. In the NMR time scale, topological constraints interfere with segmental re-orientations so that homonuclear dipolar couplings do not average to zero. The bimodal distribution was reasoned to be mainly associated with two distinct populations: cross-links in the polymer network and polymer-filler interactions. The two populations and the strength of their residual dipolar couplings were found to increase with radiation dose. DSC and solvent swelling experiments confirmed the NMR interpretation. The same research team also used NMR relaxation times and magnetic resonance imaging experiments to monitor the deformation and cross-linking in a DC745 material that was subjected to high compressive strain and gamma irradiation in a nitrogen environment. ${ }^{4,5}$ The results of 
their experiments showed a strong decrease in NMR transverse relaxation time $\left(T_{2}\right)$ with increase in the degree of cross-linking. In the present work, similar gamma doses were applied, but the material was irradiated in air instead of a nitrogen environment. It is well known that the atmosphere under which the polymer is irradiated has an effect on the nature of the chemical reactions that occur. Under inert atmosphere, radicals often tend to react to form cross-links, which increases the mechanical strength of the material. Similarly, under reactive atmosphere like air, oxygen reacts with free radicals and initiates oxidative degradation processes that can cause material hardening via oxidative cross-linking in parallel with scission reactions. At low temperatures, the presence of oxygen in the polymer or in the atmosphere may lead to formation of stable peroxides or hydroperoxides, which are likely to compete with cross-link reactions. Overall, oxygen is usually expected to increase the amount and/or rate of cross-linking and oxidative degradation of the polymer. ${ }^{6,7}$ The balance between cross-linking and scission reactions, both under inert or oxidative conditions is normally material specific and hence of primary interest in polymer radiation chemistry studies.

During this work the material was exposed up to $200 \mathrm{kGy}$ at $\mathrm{RT}$, and a comprehensive set of experimental techniques was used to detect changes in chemical, physical and mechanical properties. Solid-state and liquid-state NMR, FT-IR, Raman and mass spectroscopy were performed to monitor chemical changes, detect evolved gases and radiolysis products. Thermal analyses (TGA and DSC) were performed to investigate changes in the thermal stability and degree of crystallinity. Solvent swelling experiments were used to gauge variations in the polymer network and cross-link density, whereas imaging techniques (SEM) probed changes to the surface and cross-sections of the polymer. Electron paramagnetic resonance provided information on any stable free radicals that remained in the polymer long after gamma exposure was concluded. Finally, mechanical tests were performed to monitor changes in the macroscopic elastic properties of the material. 


\section{Materials and Methods.}

2.1 Material preparation. DC745 is a filled cross-linked copolymer that was obtained from Dow Corning as an uncured resin. It comprises a mixture of $38 \mathrm{wt} \%$ high surface area fumed silica and low surface area quartz blend with $62 \%$ reactive silicone resin. The silicone resin is composed of poly(dimethylsiloxane)-co-poly(methylphenylsilioxane) (PDMS-co-PMPS). NMR characterization of the uncured resin suggests that it contains about $98.5 \%$ dimethylsiloxane, $1.5 \%$ methylphenylsiloxane and a small amount of vinylsiloxane constituents that are converted to short chain (likely $\mathrm{N}=4$ ) alkyl crosslinking junctions during a free radical curing process. The resin is cured by thermal activation of an added peroxide initiator at $170{ }^{\circ} \mathrm{C}$ for 10 minutes. The resulting filled rubber material has a density of $1.2 \mathrm{~g} / \mathrm{cc}$. For the radiation experiments, cured DC745 samples were placed into sealed aluminum canisters in an air atmosphere. The canisters had a volume of $120 \mathrm{cc}$, and the samples occupied less than $10 \%$ of the total volume of the canister. The canisters were backfilled with dry air to about 750 torr. The average sample thickness was $0.32 \mathrm{~cm}$. Samples were exposed at the gamma irradiation facility (GIF) at Sandia National Laboratory in New Mexico using a Co-60 source (1.2 MeV). The samples were exposed at $1 \mathrm{~Gy} / \mathrm{s}(100 \mathrm{rad} / \mathrm{sec})$ to cumulative doses of $12.5,50$, and $200 \mathrm{kGy}$ at room temperature (10 kGy is equivalent to $1 \mathrm{Mrad})$. In addition, a canister containing $3.2 \mathrm{~g}$ of DC745 was also exposed to $200 \mathrm{kGy}$ at $0.25 \mathrm{~Gy} / \mathrm{s}$ to evaluate evolved gases and estimate oxygen consumption. No changes in color due to gamma exposure were observed for any of the samples investigated in this work. We also analyzed the effects of gamma irradiation on the filler present in the resin. To separate the filler from the uncured resin, a toluene and ammonium hydroxide solution was prepared containing the uncured DC745. This solution was centrifuged to separate the solute from the solid phase. This solid phase was dried overnight at $100^{\circ} \mathrm{C}$ and later analyzed by ${ }^{29} \mathrm{Si}$ MAS NMR, which established that it contained primarily inorganic material. The isolated filler was then exposed to $100 \mathrm{kGy}$ at $1 \mathrm{~Gy} / \mathrm{s}$ in air and examined by EPR to probe long-lived radicals.

2.2. Thermal Analyses. TGA experiments were performed on a Thermal Instruments Q500. Approximately 5 to $10 \mathrm{mg}$ of DC745 sample was placed in an aluminum TGA 
pan. DC745 thermo-gravimetry carried out in inert atmosphere showed a single weight loss step as commonly observed for PDMS. ${ }^{8}$ DC745 samples were subject to a selection of five temperature ramp rates (from $0.5^{\circ} \mathrm{C} / \mathrm{min}$ to $20^{\circ} \mathrm{C} / \mathrm{min}$ ) from room temperature to $600{ }^{\circ} \mathrm{C}$ under a nitrogen purge, with a flow rate of $10 \mathrm{ml} / \mathrm{min}$. The range of ramp rates was chosen in order to calculate the respective activation energies for thermal decomposition for each sample type. Kinetic information was obtained using the method proposed by Flynn and Wall for well-resolved single step decompositions and first order kinetics. ${ }^{9,10}$ The equation used was $E=-R^{*}(d \log \beta / d(1 / T))$, where $R$ is the gas constant, and $\beta$ is the heating rate. DSC experiments were performed on a TA Instruments Q2000 DSC with a quench cooling accessory. Approximately 5 to $10 \mathrm{mg}$ sample were sealed in a Tzero aluminum hermetic pan. Each sample experienced two cycles of cooling and heating; both cycles started at room temperature and ramped to a temperature of $-150{ }^{\circ} \mathrm{C}$, and then were heated to a temperature of $160{ }^{\circ} \mathrm{C}$ at $10{ }^{\circ} \mathrm{C} / \mathrm{min}$. An isothermal conditioning was performed for 15 minutes at $-150{ }^{\circ} \mathrm{C}$. The second cooling cycle was modulated at a rate of $5{ }^{\circ} \mathrm{C} / \mathrm{min}$. The first cooling and heating cycle was used to determine if any processing history was present, the second slow cooling and heating cycle was used to determine the baseline thermal characteristics. Both the temperature and heat of fusion were calibrated using the melting of high purity Indium. The pristine polymer was characterized by a melting temperature at $-43.6^{\circ} \mathrm{C}$ and a glass transition temperature at $-120^{\circ} \mathrm{C}$.

2.3. Chemical Analyses. Solid-state NMR experiments were performed using a Bruker Avance NMR spectrometer operating at $400.13 \mathrm{MHz}$ for ${ }^{1} \mathrm{H}$ and a Bruker (4 mm) MAS probe spinning at $8 \mathrm{kHz}$. The external reference used was tetramethylsilane (TMS) and about 512 scans were acquired per experiment. Liquid-state ${ }^{1} \mathrm{H}$ NMR experiments were carried out using a Bruker Avance NMR spectrometer operating at $300.13 \mathrm{MHz}$; proton signals were referenced to internal deuterated chloroform $\left(\mathrm{CDCl}_{3}\right)(99.6 \%$ deuterated from Acros Organics). Extractable material was obtained by immersing $100 \mathrm{mg}$ of DC745 in $1.5 \mathrm{~g}$ of $\mathrm{CDCl}_{3}$ overnight. Extracts were analyzed by liquid-state ${ }^{1} \mathrm{H}$ NMR. The resonance Raman spectra were recorded on a Renishaw inVia micro resonance Raman spectroscopy system, using the TE air-cooled 576 x 400 CCD array in a confocal Raman 
system (wavelength: $514 \mathrm{~nm}$ ). The incident laser power was kept at $7.37 \mathrm{~mW}$ and total accumulation times of 3 seconds were employed. The baseline was subtracted using Origin software and a fifth order polynomial function. The headspace of the canister containing the irradiated sample exposed to $200 \mathrm{kGy}$ at $0.25 \mathrm{~Gy} / \mathrm{s}$ was analyzed by mass spectroscopy (MS) using a Finnigan 271 spectrometer. Gas sample was collected into a $10 \mathrm{cc}$ gas bottle using a small vacuum manifold. An aliquot of the sample gas was injected to the mass spectrometer inlet chamber. The mass spectrometer was calibrated by known mixtures of gases, wherein detector sensitivities to the ions of specific gases are determined. When known mixtures or pure gases were not available for calibration, sensitivity estimates were provided. Initially, qualitative spectral scans were performed and unique peaks were noted for further analysis. The partial pressures of inlet gases that produced the observed ion data were deduced from detector sensitivities. The sum of the molecular gas partial pressures was normalized to the total measured inlet pressure for each sample, and the results were always within a few percent of $100 \%$. The NIST mass spectral database was consulted for assignment of hydrocarbons in the headspace analysis.

2.4. Electron Paramagnetic Resonance (EPR). Spectra were collected on a Bruker model E500 (Bruker BioSpin, Billerica, MA) operating in the X-band microwave frequency range equipped with a Bruker SHQE resonator. Continuous wave (CW) spectra were collected at temperatures from $8 \mathrm{~K}$ to room temperature. Temperature was maintained with an Oxford Instruments helium flow cryostat with an Oxford ITC temperature controller. Spectra were acquired using a modulation amplitude of $0.5-1 \mathrm{G}$, a frequency modulation of $100 \mathrm{kHz}$, an optimum microwave power of $0.001 \mathrm{~mW}$ for room temperature and $5 \mathrm{~mW}$ for low temperature, a conversion time of $164 \mathrm{~ms}$, and corresponding time constant of $164 \mathrm{~ms}$ to avoid distortion of signal. Minimal background signals were observed for an empty tube. All EPR simulations were performed within the Matlab R2013b software package (The Mathworks Inc., Natick, MA) using the EasySpin 4.5.5 toolbox. ${ }^{11,12}$ 
2.5. $X$-ray fluorescence $(X R F)$. The instrument used was a Thermo Electron Corporation ARL Quant'X EDXFR analyzer. Samples were analyzed in standard sample cups with polyethylene film used to provide maximum transparency for X-rays. Three excitation conditions were used: low atomic condition for $\mathrm{Si}, \mathrm{Ca}$, Ti, and $\mathrm{Ce} \mathrm{K}$-lines, with a 0.13$\mathrm{mm}$ aluminum filter, a tube voltage of $\sim 13-15 \mathrm{kV}$, and a live time of 200 seconds; a middle atomic number condition for $\mathrm{Ti}, \mathrm{Fe}$, and $\mathrm{Zn} \mathrm{K}$-lines, with a 0.13-mm Pd filter, a tube voltage of $\sim 35 \mathrm{kV}$, and a live time of 200 seconds; and a high atomic number condition for $\mathrm{Ce} \mathrm{K}$-lines, using a $0.63-\mathrm{mm} \mathrm{Cu}$ filter, a tube voltage of $\sim 50 \mathrm{kV}$, and a live of 200 seconds. Instrument software stores each spectrum for each condition, performs background subtraction and overlap corrections, creates peak intensity files, and performs quantitative analysis using fundamental parameter techniques. NIST 2710 algorithm was used for standardization, from which pure element count rates are determined for each element.

2.6. Solvent swelling experiments. Average molecular weights between cross-links $\left(\mathrm{M}_{\mathrm{c}}\right)$ were estimated using a two-step solvent swelling procedure described elsewhere. ${ }^{13}$ The samples $(0.5 \mathrm{~g})$ were first weighed for the initial dry weight and then immersed in $40 \mathrm{ml}$ of toluene (Fisher Scientific, 99\% purity). After equilibrium weight was reached, $4 \mathrm{ml}$ of concentrated ammonium hydroxide (Fisher Scientific, 28-30 w/w\%) was added directly to toluene. The polymer samples were then weighed periodically until equilibrium was reached with the toluene/ammonium hydroxide mixture. The additional swelling yield reflects the breaking of the hydrogen-bonding interactions between the surface silanols on the filler and the siloxane backbone of the polymer. The samples were dried under ambient conditions and a final dry weight was determined. The overall final weight loss was between 2 to $3 \%$ of the initial mass. The equilibrium weights obtained in toluene and in the toluene/ammonium hydroxide mixture were then applied to the Flory-Rehner model to estimate the average molecular weight between cross-links for the polymer and the polymer-filler composite: ${ }^{14,15}$

$$
M_{c}=\frac{\rho_{e}\left(v_{f}^{1 / 3}-v_{f} / 2\right) v_{1}}{\ln \left(1-v_{f}\right)+v_{f}+\chi v_{f}^{2}}
$$


where $\rho_{e}$ is the density of the rubber, $v_{l}=106.5$ is the molar volume of toluene, $v_{f}$ is the volume fraction of polymer in the sample at equilibrium swelling, and $\chi=0.465$ is the polymer-solvent interaction parameter. ${ }^{16}$ The average molecular weight between two neighbors cross-links is inversely proportional to the network cross-link density $\left(\mathrm{v}=\rho_{e}\right.$ $/ \mathrm{M}_{\mathrm{c}}$ ).

2.7. Scanning Electron Microscopy (SEM). Surface and cross-section samples were prepared by bisecting small sections of the rubber. The surface designates the smooth, originally manufactured surface and the cross section designates the surface generated when the rubber is cut with a razor blade. The SEM samples were then placed onto an adhesive conductive carbon tape and coated with $\mathrm{Au} / \mathrm{Pd}$ in order to minimize charging effects. Images were taken using an FEI Quanta 200 SEM with a $30 \mathrm{keV}$ beam with magnifications ranging from $\sim 100-13000$, or about $10-0.1 \mu \mathrm{m}$ resolution, respectively. All images were taken at a working distance of about $12.4 \mathrm{~mm}$. An EDS (EDAX-Ametek Genesis Liquid Nitrogen Cooled Detector System) was also used to take spectra simultaneously with the images.

2.8. Mechanical Testing. The samples used for the compression measurements were approximately $5.5 \mathrm{~mm}$ square by $3.2 \mathrm{~mm}$ thick. The low strain rate compression tests were conducted with an MTS 880 test frame equipped with a $500 \mathrm{lb}$. load cell. In addition to the load cell, a linear variable differential transducer (LVDT) and extensometer were used to accurately measure the spacing between the loading platens before and after deformation. Quasi-static and low-strain-rate compression tests were conducted at strain rates of 0.001 and $0.01 \mathrm{~s}^{-1}$. There were two temperature regions of interest, one being between $-60^{\circ} \mathrm{C}$ and $-50^{\circ} \mathrm{C}$, where the crystallization/melting occurs, and room temperature. Low temperature experiments were conducted using a cold stage that was temperature regulated with flowing cold nitrogen gas. For all experiments, a boron nitride lubricant was used to reduce the effects of friction during sample deformation. Optically flat tungsten carbide platens were used for the compression tests. Before the compression tests were performed a small preload was exerted on the sample to establish even contact. This contact allowed for better thermal conductivity and a uniform total strain from one sample to the next. Room temperature compression tests were performed at a strain rate 
of $0.001 \mathrm{~s}^{-1}$ and the low temperature tests were run at a strain rate of $0.01 \mathrm{~s}^{-1}$. Due to the viscoelastic nature of DC745, above the phase transition temperature all experiments were run with three load/unload cycles. Before the compression tests were performed, the temperature was held constant $\pm 0.5^{\circ} \mathrm{C}$ for 5 minutes. The low temperature mechanical experiments were held at the test temperature for at least 50 minutes $\pm 2{ }^{\circ} \mathrm{C}$.

\subsection{Oxygen Permeability and Consumption Measurements. Oxygen permeation} experiments were performed using a custom modified commercial Oxtran-100 coulometric permeation apparatus (Modern Controls, Inc., Minneapolis, MN). The instrument is based on the ASTM standard test method D-3985-81. Details of the technique have been described elsewhere. ${ }^{17}$ The consumption of oxygen was determined as a function of dose rate at $0.055 \mathrm{~Gy} / \mathrm{s}, 0.1 \mathrm{~Gy} / \mathrm{s}$ and $1 \mathrm{~Gy} / \mathrm{s}$ using an Oxzilla II Dual Absolute and Differential Oxygen Analyzer from Sable Systems International (Las Vegas, NV), and at 0.25 Gy/s using a Finnigan 271 spectrometer.

\section{Results and Discussion.}

\subsection{Diffusion-Limited Oxidation Effects.}

It is important to evaluate if diffusion limited oxidation (DLO) effects can influence the degradation behavior, especially due to the relatively high dose rates used in this work. ${ }^{18}$ When DLO conditions apply, sample specimens will not age homogeneously and trends in the material properties will be masked by a combination of inert and oxidative processes. DLO effects are minimal when the sample thickness is less than the maximum allowable thickness, which is given by:

$$
L_{90}=\left[\frac{\alpha_{c} * p * P_{o x}}{(\beta+1) * \phi_{0} * I * \rho * 22400}\right]^{0.5}
$$

where $p$ is the initial pressure inside the canister $[\mathrm{cmHg}] ; \mathrm{P}_{\mathrm{ox}}$ is the oxygen permeability coefficient of the material $[\mathrm{ccSTP} / \mathrm{cm}-\mathrm{cmHg}-\mathrm{s}] ; \Phi_{0}$ is the oxygen consumption rate $[\mathrm{mol} / \mathrm{g}-\mathrm{Gy}] ;$ I the dose rate $[\mathrm{Gy} / \mathrm{s}] ; \rho$ is the sample density $[1.2 \mathrm{~g} / \mathrm{cc}]$; and the factor 
$\frac{\alpha_{c}}{\beta+1}$ ranges from 2.4 to 6.7 as $\beta$ (oxidation rate dependence on partial pressure) varies from 1 to 10 , respectively. ${ }^{19,20}$ Existing radiation studies for other polymers with careful DLO profile analysis have shown that $\beta$ under radiation-oxidative is generally slightly larger than under purely thermal aging conditions. ${ }^{19,20}$ We believe that $\beta=7$ is a reasonable value for this material under the exposure conditions.

The oxygen consumption rate was obtained by methods previously described elsewhere $^{21,22}$ under controlled air and non-DLO conditions. It was determined as $5 \mathrm{e}^{-10}$ $\mathrm{mol} / \mathrm{g}-\mathrm{Gy}$ at $1 \mathrm{~Gy} / \mathrm{s}$ corresponding to a rate of $5 \mathrm{e}^{-10} \mathrm{~mol} / \mathrm{g} / \mathrm{s}$, and $9 \mathrm{e}^{-10} \mathrm{~mol} / \mathrm{g}-\mathrm{Gy}$ at 0.055 Gy/s. Usually, when the degradation is dominated by irradiation, which is normally the case at low temperature unless very low dose rates are applied, the oxidation rate in mols/g/Gy is independent of dose rate. Interestingly, here there is some evidence that the oxidation rate decreases slightly with increasing dose rate. There is precedent for dose rate effects on silicone rubber materials as demonstrated by Rost and co-workers. ${ }^{23}$ The oxygen permeability for DC745 at room temperature was measured to be $5.3 \mathrm{e}^{-8}$ $\mathrm{ccSTP} / \mathrm{cm}-\mathrm{s}-\mathrm{cmHg}$, which is close to the $10^{-8} \mathrm{ccSTP} / \mathrm{cm}-\mathrm{s}-\mathrm{cmHg}$ value previously reported at $35^{\circ} \mathrm{C}$ for PDMS containing 4.9 vol\% silica. ${ }^{24}$ Before DLO complicates the aging process, the estimated maximum thickness with all the parameters defined above is approximately $\mathbf{5 . 8} \mathbf{m m}$, as obtained by equation (2).

\section{1.a. Estimation of maximum non-DLO oxidation rate and DLO profiles.}

With the measured permeability and known values for density and thickness, plus estimation for beta (7) under radiation conditions yielding $\frac{\alpha_{c}}{\beta+1}=5.5$, it is possible to estimate a maximum oxidation rate for which DLO effects are not important, i.e. when 90\% homogeneous oxidation applies. This profile is shown in Figure 1 and implies that any oxidation rate greater than $1.7 \mathrm{e}^{-9} \mathrm{mols} / \mathrm{g} / \mathrm{s}$ will result in more pronounced degradation profiles and hence reflects the transition to DLO behavior (90\% plot in Figure 1). With a measured oxidation rate of $5 \mathrm{e}^{-10} \mathrm{~mol} / \mathrm{g} / \mathrm{Gy}$ for this material this will occur at a dose rate of $3.4 \mathrm{~Gy} / \mathrm{s}$. Since the experiments here were conducted at a lower dose rate of $1 \mathrm{~Gy} / \mathrm{s}$, i.e. below this boundary value, it is expected that DLO behavior does 
not participate in this accelerated aging process. Figure 1 shows the corresponding profile for $5 \mathrm{e}^{-10} \mathrm{~mol} / \mathrm{g} / \mathrm{Gy}$ and $\beta=7$ (blue curve). The predicted profile for $5 \mathrm{e}^{-10} \mathrm{~mol} / \mathrm{g} / \mathrm{s}$ for a beta of 1 is also shown (red curve) and predicts a slightly more pronounced profile, but still falling short of any DLO effect to be concerned about. Additional experiments revealed a similar oxidation rate of $\sim 5 \mathrm{e}^{-10} \mathrm{~mol} / \mathrm{g}$-Gy for samples exposed at $0.1 \mathrm{~Gy} / \mathrm{s}$ (using traditional oxuptake ampoules with gas chromatography (GC) analysis at Sandia National Laboratory) and at $0.25 \mathrm{~Gy} / \mathrm{s}$ (using MS headspace analysis at LANL). The slightly enhanced oxidation rate towards lower dose rates is not easily explained, but may simply reflect the underlying material behavior. Most importantly, DLO conditions for the aging of this material can be ruled out at the dose rate applied, based on measured oxidation rates, permeability, and also when accommodating some variance in beta.

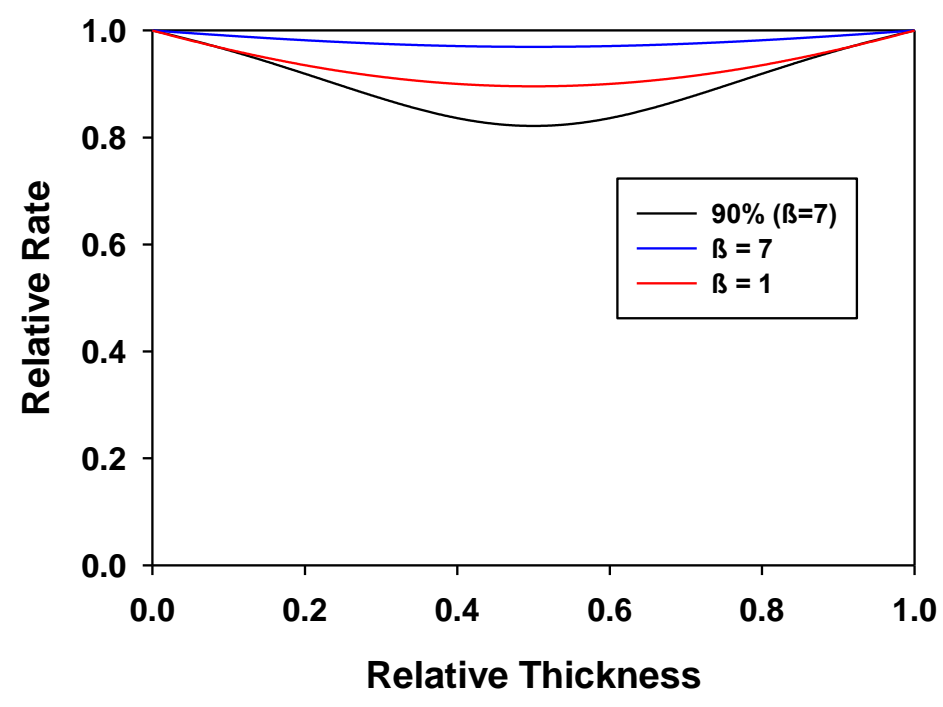

Figure 1. Modeled DLO profiles providing local oxidation rates. The $90 \%$ profile as the accepted transition between DLO and non-DLO for $\beta=7$ occurs at $1.7 \mathrm{e}^{-9} \mathrm{mols} / \mathrm{g} / \mathrm{s}$. Also shown are the predicted oxidation profiles for $\Phi_{0}=5 \mathrm{e}^{-10} \mathrm{~mol} / \mathrm{g} / \mathrm{Gy}, \beta=7$, and $\mathrm{I}=1 \mathrm{~Gy} / \mathrm{s}$ (blue curve), and $\Phi_{0}=5 \mathrm{e}^{-10} \mathrm{~mol} / \mathrm{g} / \mathrm{Gy}, \beta=1$, and $\mathrm{I}=1 \mathrm{~Gy} / \mathrm{s}$ (red curve), respectively. The other parameters for these predictions are: $\mathrm{P}_{\mathrm{ox}}=5.3 \mathrm{e}^{-8} \mathrm{cSTP} / \mathrm{cm}-\mathrm{cmHg}-\mathrm{s}$, thickness of $3.2 \mathrm{~mm}$, density $1.2 \mathrm{~g} / \mathrm{cc}$, and air exposure at 750 Torr.

\section{1.b. Consumption of oxygen during the radiation exposure.}


Experiments were conducted with relatively large sample amounts in parallel with a significant oxidation rate. The effective oxidation rate was not known initially, but was sufficiently high that total oxygen consumption could not be neglected during the experiment. Calculations of cumulative oxygen consumption expressed as residual $\mathrm{O}_{2}$ partial pressure are shown in Figure 2 for a number of conditions, i.e. rates and sample weights. Oxidative conditions will be maintained for small sample weights and the lower rate of $5 \mathrm{e}-10 \mathrm{~mol} / \mathrm{g} / \mathrm{s}$. It is also clear that the large samples prepared in this study at $5^{-10}$ mols $/ \mathrm{g} / \mathrm{s}$ will be sufficiently oxidative in nature at 12.5 and $50 \mathrm{kGy}$, but for the $200 \mathrm{kGy}$ sample oxygen will be completely consumed, such that the aging conditions change from oxidative to inert during the experiment.

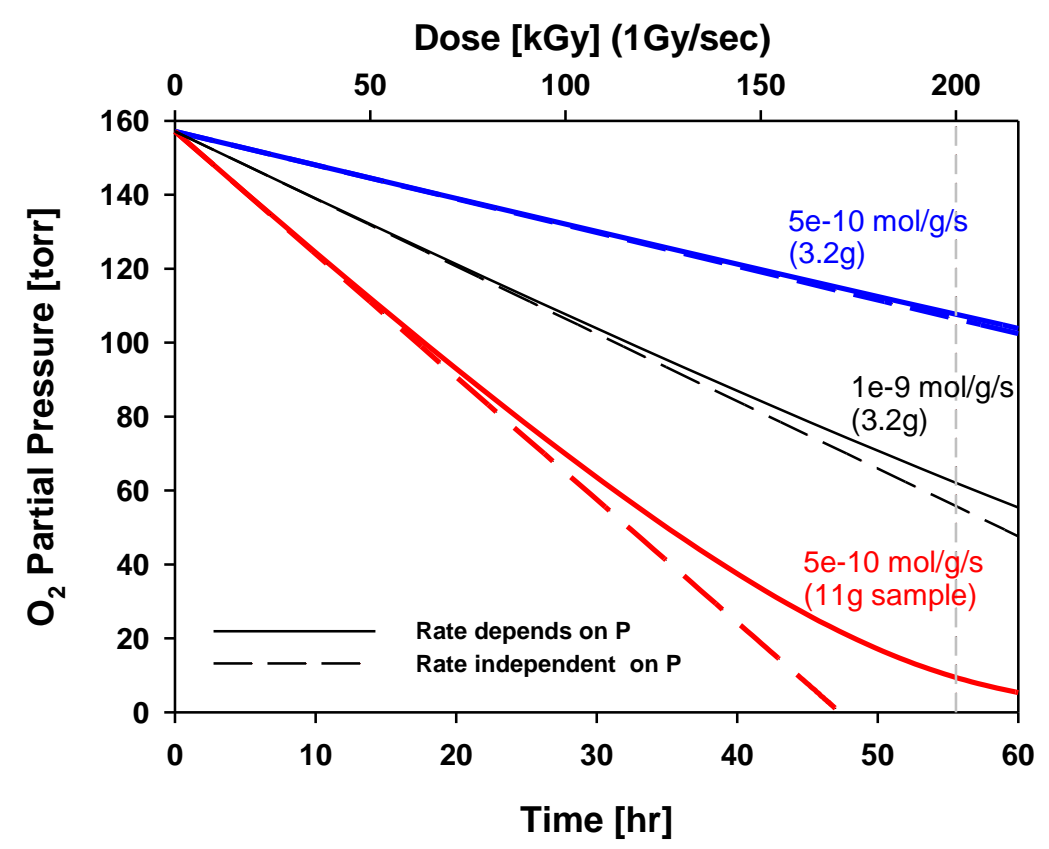

Figure 2. Predicted oxygen partial pressure depletion during radiation aging under nonDLO conditions for various rates and weights in a sealed container of $120 \mathrm{cc}$ with 750 Torr of air. Linear predictions are obtained assuming a constant ox-rate; when a rate dependence on pressure is taken into account $(\beta=7)$ the effective rate drops and consumption slows down somewhat (curved predictions).

\subsection{Changes in Thermal Properties.}


TGA experiments were performed to investigate changes in the thermal stability of DC745 samples exposed to gamma irradiation. The activation energy associated with the thermal decomposition can be estimated by performing TGA experiments over a range of heating rates. An increase in the thermal stability of the material with increasing radiation exposure was observed. At a $5 \%$ mass loss there is nearly a $10^{\circ} \mathrm{C}$ increase in the thermal stability between the control and the sample irradiated to $200 \mathbf{~ k G y}$. The increased stability is rationalized by the additional cross-linking sites that are formed due to gamma exposure under evolving inert conditions at the later stage of degradation beyond $\mathbf{5 0}$ kGy. ${ }^{25}$ The corresponding estimates of the activation energies of the thermal decomposition are detailed in Table 1.

DSC experiments were performed to monitor changes in the degree of crystallinity due to gamma exposure. The amount of crystallinity is an important parameter that influences the mechanical response of the material, since crystallites function as physical cross-linking sites. Typically, PDMS copolymers crystallize if the non-crystallizable co-monomers are less than $7 \mathrm{~mol} \%$. DC745 resin contains around 1.5 mol\% methyl vinyl siloxane and methyl phenyl siloxane; therefore we expect this polymer to exhibit crystallization. In addition, radiolysis has the potential to change the level of crystallization of the material by inducing cross-linking and/or chain scission. The results from the DSC are shown in Figure 3. Cooling-heating cycles reveal the presence of one sharp exotherm and one endotherm peak that are clearly associated with crystallization and melting. In particular, the endotherm peak shifts from -43.6 to $49.4^{\circ} \mathrm{C}$, whereas the heat of crystallization decreases from 12.79 to $10.81 \mathrm{~J} / \mathrm{g}$ respective to increasing radiation dose. The crystallization temperature decreases by $9^{\circ} \mathrm{C}$ for the sample exposed to $200 \mathrm{kGy}$ when compared to the control. Overall, a decrease in the estimated amount of crystallinity is observed with increased radiation dose. (\% crystallinity $=100 * \Delta \mathrm{H}_{\mathrm{f}} / \Delta \mathrm{H}_{\mathrm{f}}{ }^{0}$, with $\Delta \mathrm{H}_{\mathrm{f}}{ }^{0}=61.3$ or $37.4 \mathrm{~J} / \mathrm{g}$ ). ${ }^{26,27}$ These values are listed in Table 1. This result may be reasoned in terms of an increase in the cross-link density that hinders the ability of the chains to crystallize, either by decreasing chain mobility and or by decreasing the size of the crystalline domains. No significant changes were observed in $\mathrm{Tg}$ for irradiated samples when compared to control samples. 


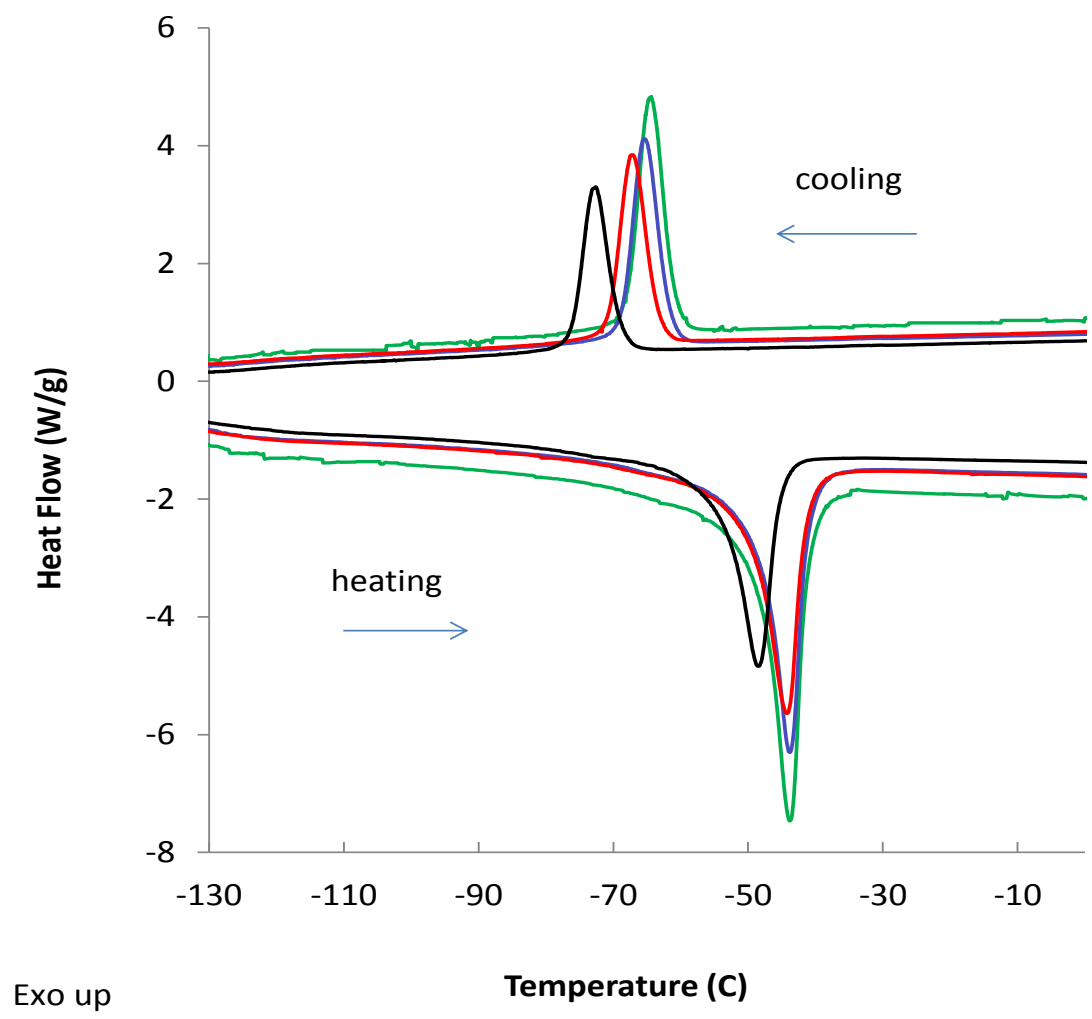

Figure 3. DSC thermograms showing cooling and heating cycles for irradiated $12.5 \mathrm{kGy}$ (blue trace), $50 \mathrm{kGy}$ (red trace), $200 \mathrm{kGy}$ (black trace) and control sample (green trace).

Table 1. Thermal decomposition activation energies and DSC results for irradiated and control samples.

\begin{tabular}{|c|c|c|c|c|}
\hline Sample & $\begin{array}{c}\text { Activation } \\
\text { Energy* } \\
{[\mathrm{kJ} / \mathrm{mol}]}\end{array}$ & $\begin{array}{c}\text { Heat of Fusion } \\
{[\mathrm{J} / \mathrm{g}]}\end{array}$ & $\begin{array}{c}\text { Melting } \\
\text { Temperature }\left[{ }^{\circ} \mathrm{C}\right]\end{array}$ & $\begin{array}{c}\text { Percent } \\
\text { Crystallinity** }\end{array}$ \\
\hline Control & 154.5 & 12.79 & -43.6 & 34.8 \\
\hline $12.5 \mathrm{kGy}$ & 154.2 & 12.84 & -44.7 & 35.0 \\
\hline $50 \mathrm{kGy}$ & 161.7 & 12.01 & -45.2 & 32.7 \\
\hline $200 \mathrm{kGy}$ & 164.2 & 10.81 & -49.4 & 29.5 \\
\hline
\end{tabular}


*Estimated at $5 \%$ mass loss. **Percent crystallinity estimated using $\Delta \mathrm{H}_{\mathrm{f}}{ }^{0}=37.4 \mathrm{~J} / \mathrm{g}$. The $200 \mathrm{kGy}$ sample has a significant degree of non-oxidative radiation chemistry from the oxygen depleted later stage of exposure.

\subsection{Changes in Solvent Uptake.}

The degree of cross-linking in rubbery materials such as DC745 has a large influence on the mechanical response of the material. For instance, an increase in crosslink density leads to considerable increase in elastic modulus and hardness, accompanied by a reduction in elongation and permanent set. ${ }^{28}$ Cross-link density or the average molecular weight between two adjacent cross-links can be estimated from different methods with equilibrium solvent swelling being one of the most common. The wellknown Flory-Rehner theory relates solvent swelling values to cross-link density through the polymer-solvent interaction parameter. ${ }^{15,29}$

In filled elastomers, such as DC745, there are physical and chemical interactions between the polymer and the filler surface, in addition to covalent cross-links and entanglements between polymer chains. Therefore, a modified solvent swelling procedure is used to discriminate between these two contributions to the total cross-link density. ${ }^{13}$ The two-step swelling method uses ammonium hydroxide to separate the polymer chains from the filler. While this approach is used widespread, the effects of ammonium hydroxide have not been investigated. Therefore we performed ${ }^{15} \mathrm{~N}$ NMR spectroscopy to investigate DC745 samples that were exposed to isotopically enriched

${ }^{15} \mathrm{~N}$ ammonia gas. Our results indicate that only NMR signals associated with ammonia gas being adsorbed on the surface of the filler were observed, indicating that exposure of DC745 to ammonium hydroxide is unlikely to promote undesirable chemical reactions in the rubber (see Figure 1 in the Supporting Information).

Solvent swelling experiments shown in Figure 4 were performed to assess changes in the average molecular weight between cross-links $\left(\mathrm{M}_{\mathrm{c}}\right)$ due to gamma exposure. $\mathbf{M}_{\mathrm{c}}$ estimation for samples swollen in toluene reveals contributions from both covalent cross-links and polymer-filler interactions, as opposed to samples swollen in the toluene/ammonium hydroxide mixture, where $\mathrm{M}_{\mathrm{c}}$ reflects only contributions from covalent cross-links. As shown in Figure 4 , the changes in $\mathrm{M}_{\mathrm{c}}$, as estimated by both 
swelling methods, seem to follow the same trend with gamma exposure. At low doses (12.5 to $50 \mathrm{kGy}$ ), there are little variations in both $\mathrm{M}_{\mathrm{c}} \mathrm{s}$. However, at the highest gamma dose there is a significant decrease in solvent uptake, indicating that overall the polymer became significantly more cross-linked. $\mathrm{M}_{\mathrm{c}}$ for the $200 \mathrm{kGy}$ sample decreases by $16 \%$ in toluene and $19 \%$ in the toluene/ammonium hydroxide when compared to the control sample. This decrease seems to be primarily due to an increasing in covalent cross-link formation with little contribution from changes in polymer-filler interactions. Earlier work performed on the same material has shown that increasing the irradiation dose under a nitrogen atmosphere resulted in increasing the overall cross-link density of the polymer. ${ }^{30}$ This increase was due to contributions from both, covalent cross-links and polymer-filler interactions. The same authors postulated that polymer-filler interactions were enhanced by dose exposure due to $i$ ) more polymer chains being adsorbed to the filler surface, and ii) polymer chains within the network cross-link to the chains near the filler particles. ${ }^{30}$ Our solvent swelling experiments indicated that exposure in air may not enhance polymer-filler interactions as much as gamma exposure in the evolving nitrogen environment beyond the $\mathbf{5 0} \mathbf{~ k G y}$ exposure.

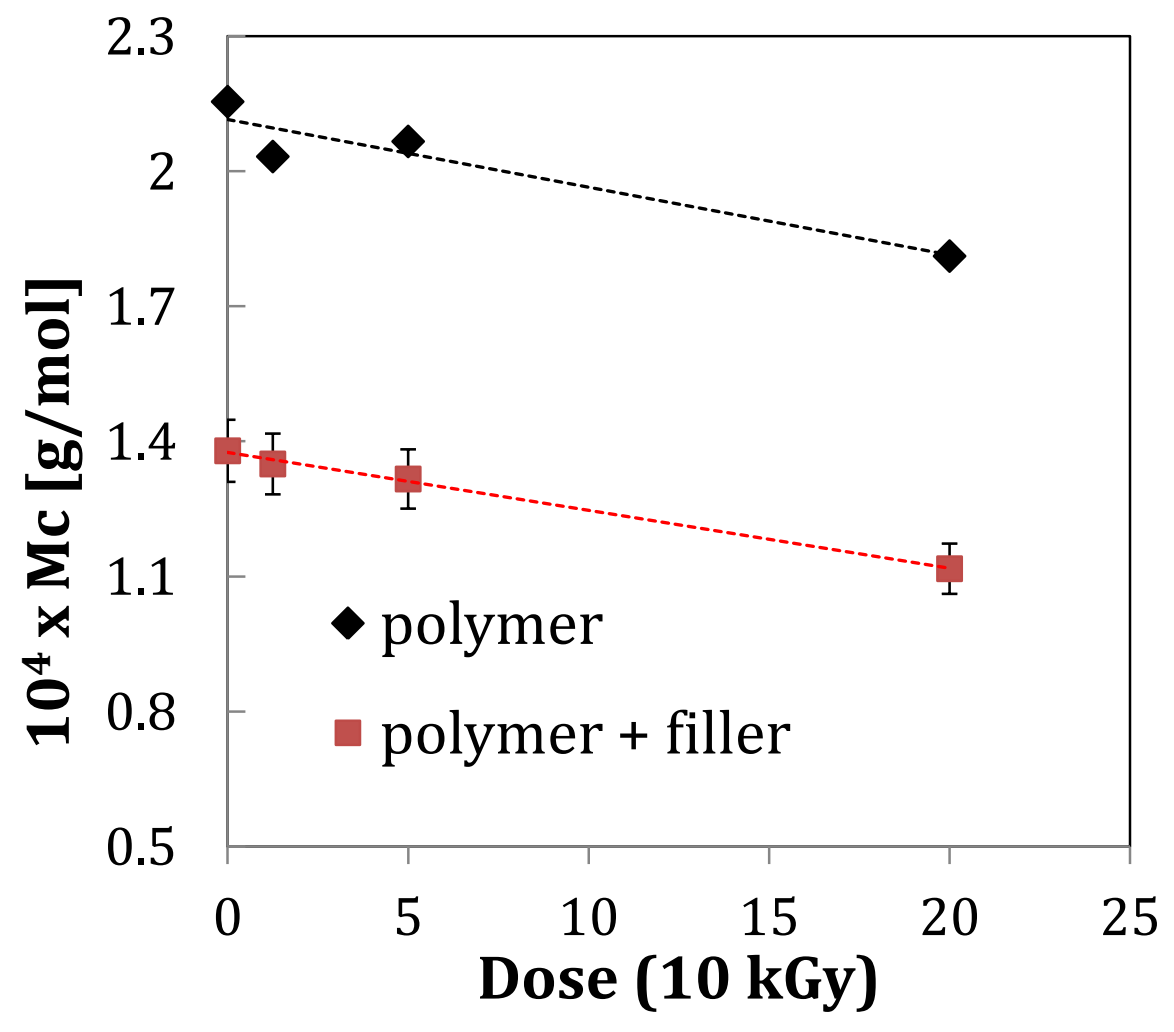


Figure 4. Plot of $\mathrm{M}_{\mathrm{c}}$ as a function of gamma exposure for DC745 samples exposed to gamma irradiation at doses of 0,12.5, 50 (oxidative) and $200 \mathrm{kGy}$ (inert contribution). Polymer refers to samples swollen in the toluene/ammonium hydroxide mixture, and polymer + filler refers to samples swollen in toluene only.

\subsection{Changes in Chemistry.}

NMR, Raman and FT-IR spectroscopy were performed on DC745 samples to detect chemical changes induced by gamma exposure. FT-IR spectra detected no significant differences between the gamma-irradiated and the control samples. Solid-state NMR was performed to identify the presence of new peaks in the ${ }^{1} \mathrm{H}$ MAS NMR spectrum. Figure 5 shows that NMR spectra are mainly composed of a sharp signal near 0 ppm, which is associated with methyl groups from the polymer backbone, and a small broad peak at $7.12 \mathrm{ppm}$ that is due to protons from phenyl groups. These spectra illustrate the challenge of detecting chemical changes for samples exposed to moderate doses of gamma radiation. A series of very small peaks appear between 2.45 to $5.38 \mathrm{ppm}$ for the samples that received the highest dose, with the largest peak at $3.38 \mathrm{ppm}$. These signals are associated with radiolysis, as they are only observed for samples exposed to gamma irradiation. Typically, exposure of siloxanes to radiation will induce radicals due to chain scission; macroradicals due to methyl or hydrogen abstraction; and finally, $\mathrm{H}$ and $\mathrm{Y}$ types cross-links as detailed elsewhere. ${ }^{6,31}$ Thus, peaks associated with methylene protons (1.2 to $1.7 \mathrm{ppm}$ ) are expected to be observed in the NMR spectrum, but these are very difficult to detect due to their likely low intensity, presence of already existing alkyl cross-linking junctions in the initial resin, and overlap with the large peak at $0 \mathrm{ppm}$. In addition, since these samples were irradiated in air, oxygen may have reacted with radiation-induced free radicals to produce inactive species that cannot contribute to cross-linking reactions. ${ }^{6}$ Thus, these small peaks observed in the NMR spectrum of the sample irradiated to the highest dose could be associated with long-lived peroxide radicals or reflects the transition to a more inert dominated aging condition. 


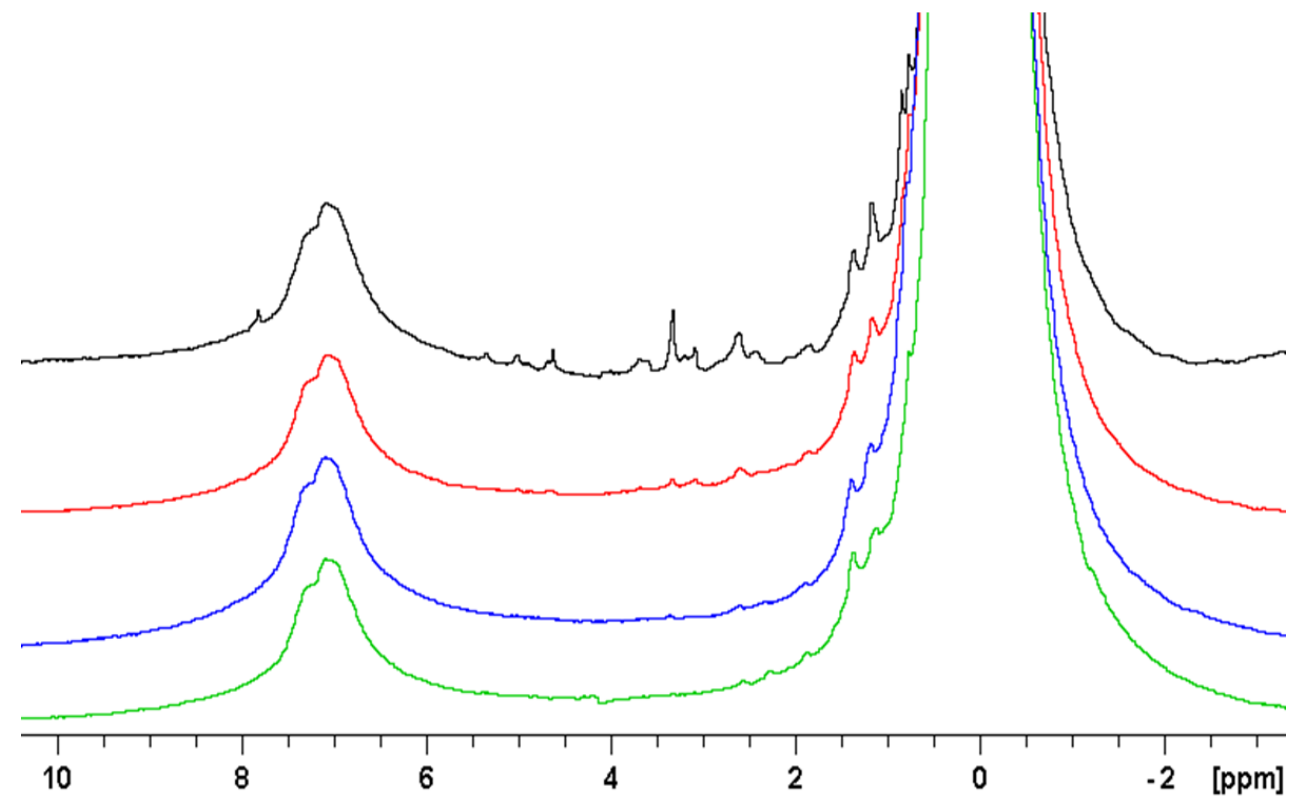

Figure 5. ${ }^{1} \mathrm{H}$ MAS NMR spectra obtained for irradiated samples: $12.5 \mathrm{kGy}$ (blue trace), $50 \mathrm{kGy}$ (red trace), $200 \mathrm{kGy}$ (black trace), and control sample (green trace).

Low molecular weight compounds, which are likely to be indicative of chain scission, were also isolated from the irradiated polymer network by extracting the rubber in $\mathrm{CDCl}_{3}$. The sample extracts were evaluated by liquid-state ${ }^{1} \mathrm{H} \mathrm{NMR}$ spectroscopy to detect chemical signatures associated with radiolysis. Figure 6 shows ${ }^{1} \mathrm{H}$ NMR spectra of the extractable material. The spectra are similar to each other in chemical composition and amount of extracts. The largest peak is associated with methyl groups from PDMS chains, followed by residual protons from the solvent at $7.25 \mathrm{ppm}$, and water at $1.56 \mathrm{ppm}$. The small peaks between 0.8 to $1.4 \mathrm{ppm}$ are likely due to impurities found within the polymer, as they are consistent throughout. However, for the sample exposed at the highest dose, we clearly observe a new signal with a small intensity at $7.98 \mathrm{ppm}$. This signal was also observed in the solid-state NMR spectrum for the same sample. Nonetheless, without further characterization this peak is difficult to assign. 


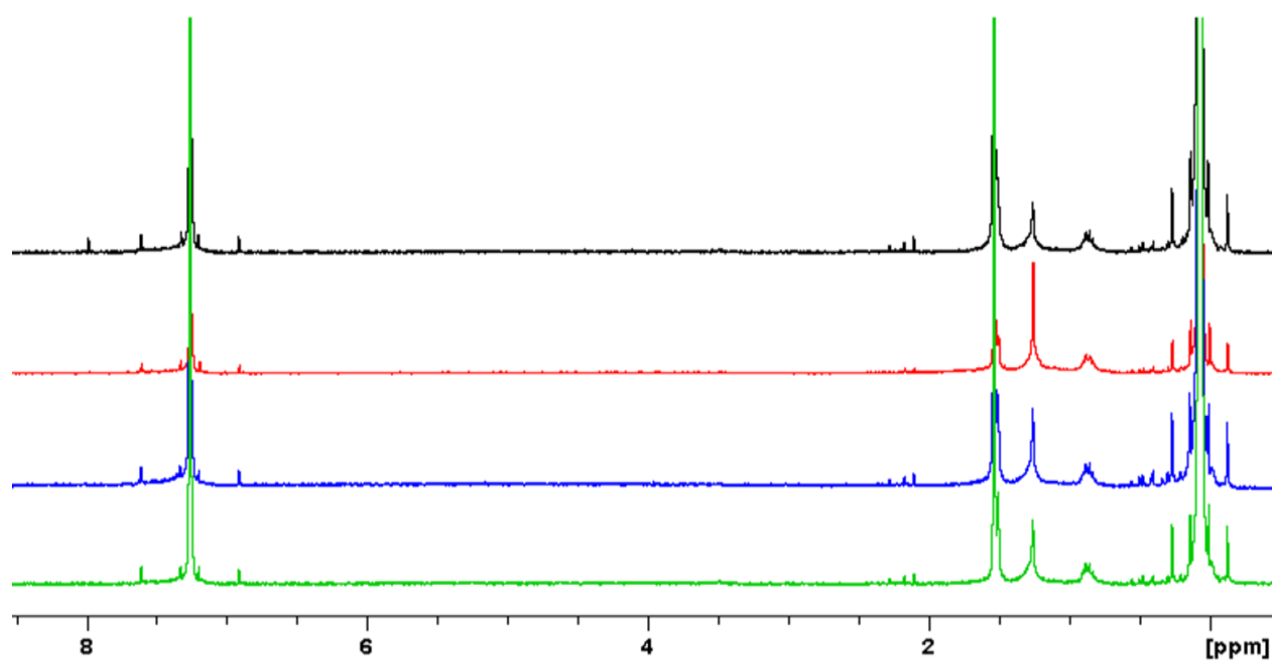

Figure 6. ${ }^{1} \mathrm{H}$ NMR spectra of extractable material obtained from DC745 samples that were irradiated at doses of $12.5 \mathrm{kGy}$ (blue trace), $50 \mathrm{kGy}$ (red trace) and $200 \mathrm{kGy}$ (black trace). The green trace represents extracts from the control sample.

The resonance Raman spectra of the DC745 samples exhibit a number of bands as seen in Figure 7. The most intense is due to the $\mathrm{Si}-\mathrm{O}-\mathrm{Si}$ symmetric stretching frequency that appears at $492 \mathrm{~cm}^{-1}$. The shoulder near $465 \mathrm{~cm}^{-1}$ can also be assigned to the symmetric stretching of $\mathrm{Si}-\mathrm{O}-\mathrm{Si}$ found in backbone of the polymer. The next most intense band arises from the symmetric rocking of the $\mathrm{Si}-\mathrm{CH}_{3}$ groups, this band appears at $687 \mathrm{~cm}^{-1}$. The band that appears as a shoulder at $618 \mathrm{~cm}^{-1}$ is from $\mathrm{SiO}_{3}$ from bending mode. A band at $999 \mathrm{~cm}^{-1}$ corresponds to the aromatic ring bending. Bands at $1256 \mathrm{~cm}^{-1}$ and $1408 \mathrm{~cm}^{-1}$ correspond to $-\mathrm{CH}_{3}$ symmetric and asymmetric bending, respectively. While there are a number of additional less intense bands, there does not appear to be any change in the intensity of any of the bands upon irradiation of the polymer.

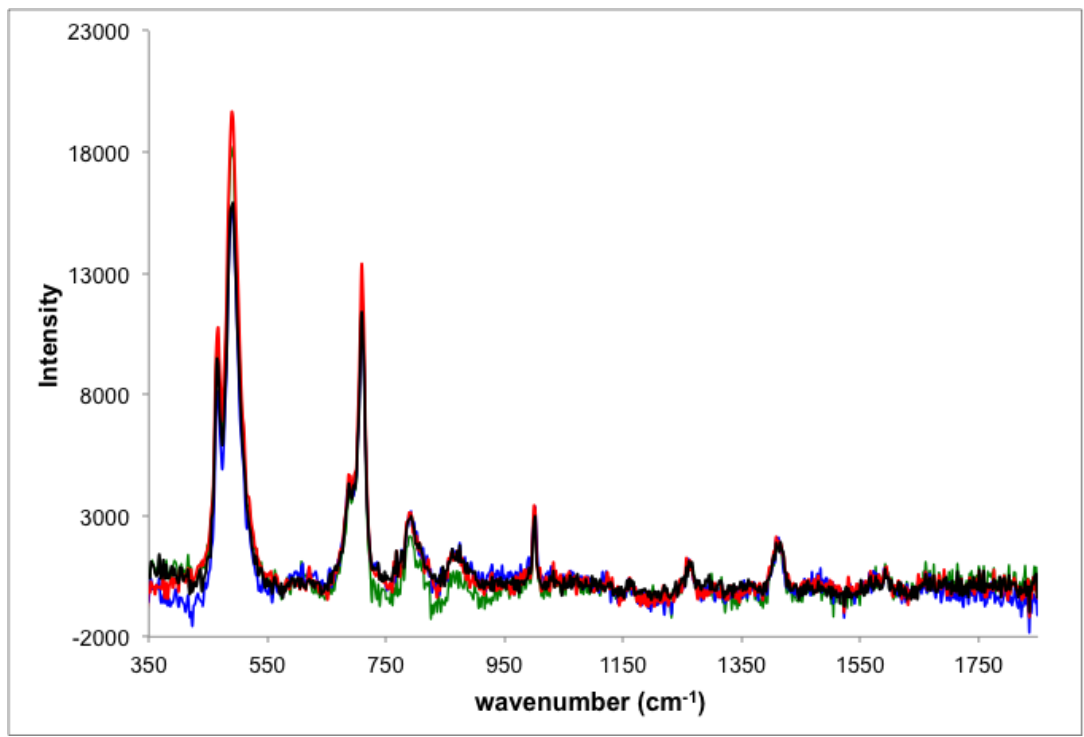


Figure 7. Raman spectra obtained for the control (green trace) sample and samples irradiated at doses of $12.5 \mathrm{kGy}$ (blue trace), $50 \mathrm{kGy}$ (red trace) $200 \mathrm{kGy}$ (black trace). The green trace represents extracts from the control sample.

MS was used to probe the gases that result from exposing DC745 to ionizing irradiation. Numerous investigators have observed the evolution of hydrogen, methane and ethane from PDMS radiolysis, over a wide range of experimental conditions and dose rate. $^{2}$ In addition to these gases, carbon dioxide and carbon monoxide were also detected, resulting from exposing the material to gamma irradiation in air. ${ }^{7} \mathrm{~A}$ decrease in the oxygen concentration owed to oxidative degradation was observed as well. These results are listed in Table 2.

Table 2. Headspace composition of the sample (3.2 $\mathbf{~ g})$ irradiated to $200 \mathrm{kGy}$ at $0.25 \mathrm{~Gy} / \mathrm{s}$ in air. Concentrations are given in mole- $\%$.

\begin{tabular}{|c|c|c|c|c|c|c|c|c|c|}
\hline $\mathrm{H}_{2}$ & $\mathrm{CH}_{4}$ & $\mathrm{CO}$ & $\mathrm{N}_{2}$ & $\mathrm{C}_{2} \mathrm{H}_{6}$ & $\mathrm{O}_{2}$ & $\mathrm{CH}_{3} \mathrm{OH}$ & $\mathrm{Ar}$ & $\mathrm{CO}_{2}$ & Benzene \\
\hline 0.36 & 0.19 & 0.34 & 81.21 & 0.11 & 15.58 & 0.05 & 0.98 & 1.06 & 0.004 \\
\hline
\end{tabular}

\subsection{Changes on the Surface and Cross-Section.}

Variations on the surface and cross-sections of DC745, including information on physical and chemical defects, morphology (texture), and chemical composition were investigated by SEM and EDS techniques. SEM images of cross-sections and surfaces of irradiated and control samples are shown in Figures 8 and 9. No clear differences were observed between irradiated and control samples. This is most likely due to the inhomogeneity of DC745, which renders small changes difficult to be explicitly assigned to radiolytic and/or oxidative damage. 

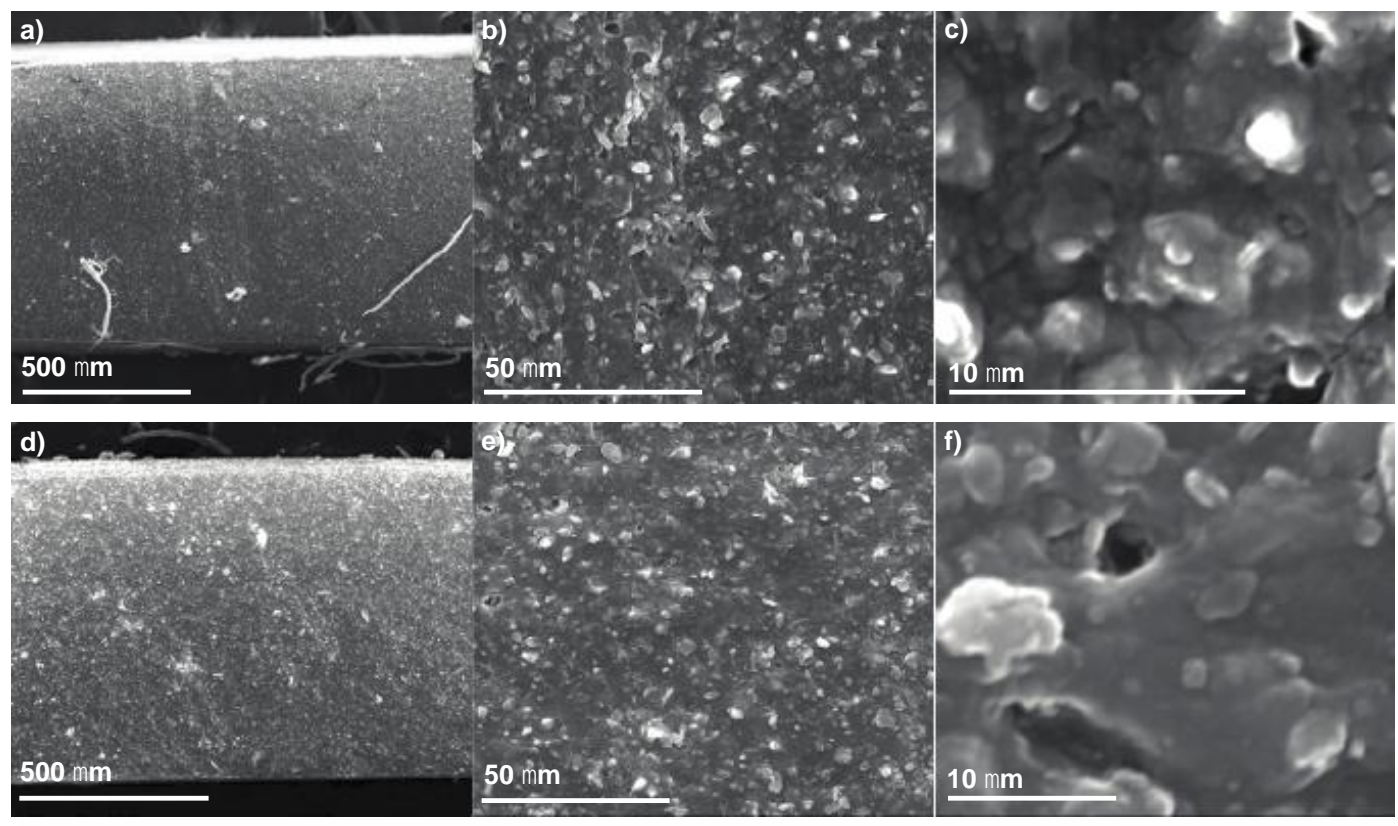

Figure 8. SEM images of the cross-section of DC745 for the control sample (top images), and sample exposed to $200 \mathrm{kGy}$ dose at $1 \mathrm{~Gy} / \mathrm{s}$ (bottom images). From left to right, the SEM images were collected from 500, 50 and $10 \mu \mathrm{m}$.
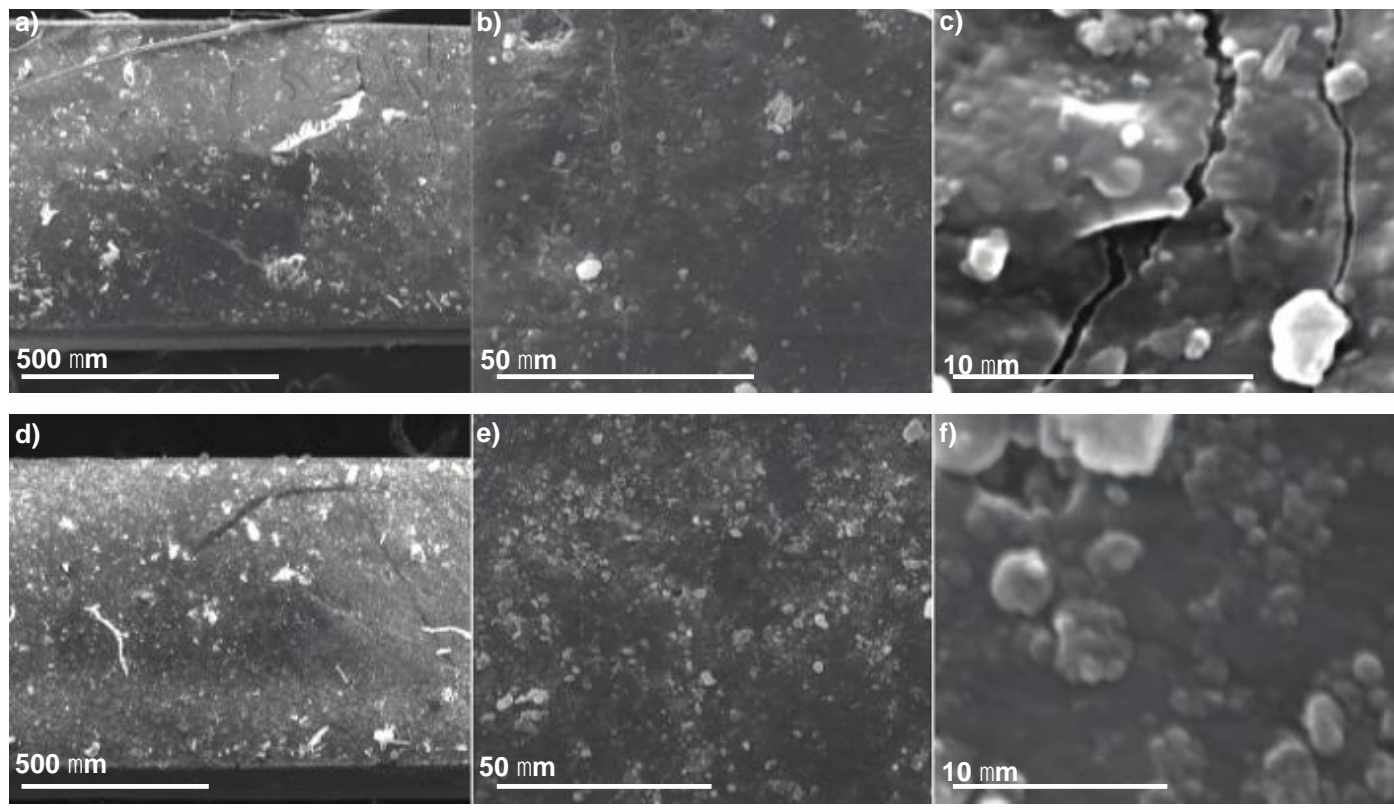

Figure 9. SEM images of the surface of DC745 for the control sample (top images), and $200 \mathrm{kGy}$ sample (bottom images). From left to right, the SEM images were collected from 500,50 and $10 \mu \mathrm{m}$. 
EDS is a technique useful for providing information on the chemical composition of a material as shown in Figure 10. The most prominent peaks are associated with carbon, oxygen and silicon for control and irradiated samples. The surface of the $200 \mathrm{kGy}$ shows a peak that is correlated to magnesium. This peak is not present on the surface of the control sample; therefore it is attributed to sample contamination or to small amounts of magnesium being in the filler particles. Due to the inhomogeneous nature of the material it is possible that levels of contaminates or impurities vary from sample to sample. Overall, gamma irradiation had no detectable effect on the chemical composition of surface and cross-section of the irradiated samples.
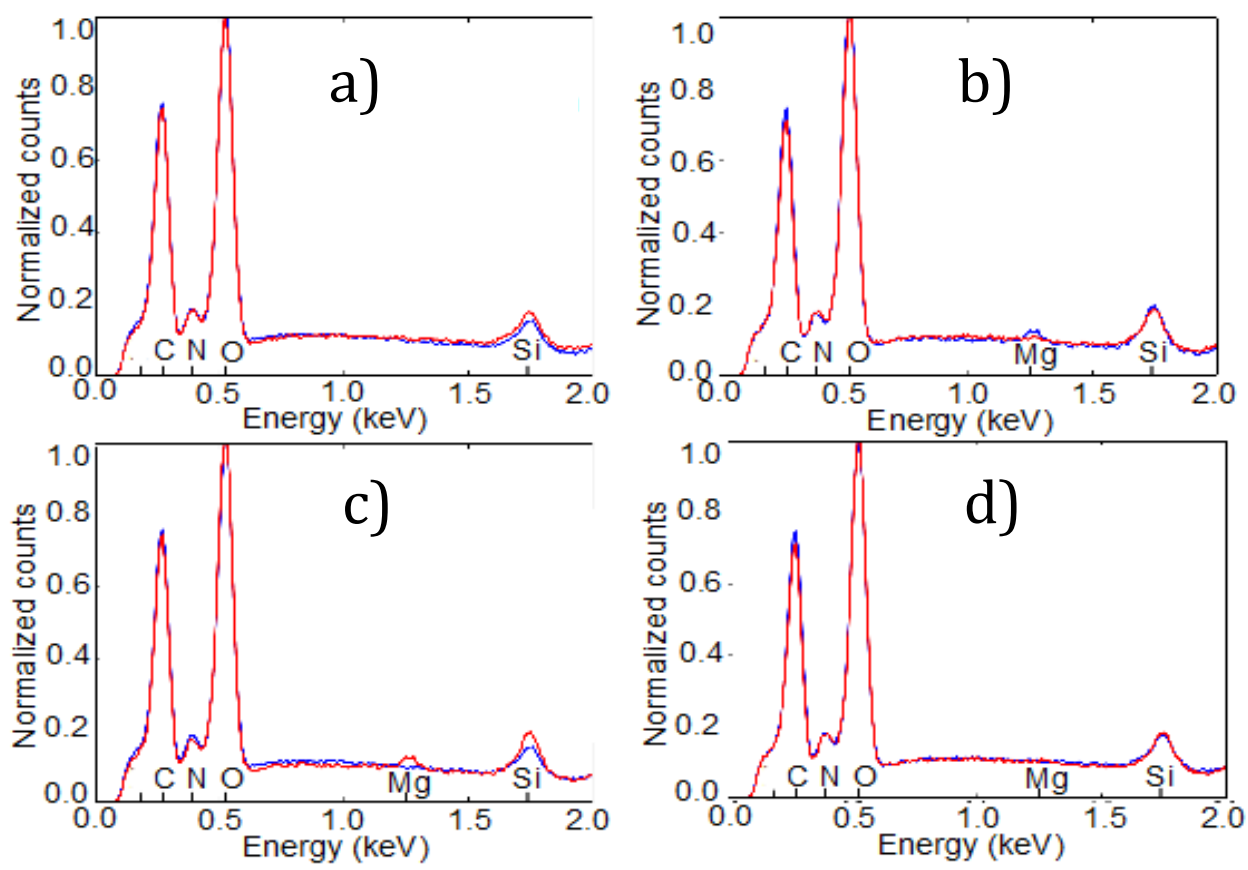

Figure 10. Chemical information from EDS data on the surfaces and cross-sections of $200 \mathrm{kGy}$ and control samples. a) Control sample (surface and cross section), b) $200 \mathrm{kGy}$ sample (surface and cross section), c) Comparison between surfaces of the control and $200 \mathrm{kGy}$ samples, and d) Comparison between cross-sections of the control and $200 \mathrm{kGy}$ samples. 


\subsection{Presence of Free Radicals.}

EPR spectroscopy is among one of the best methods for determining the spin topography and identity of molecules containing unpaired electrons. The hyperfine coupling constant (hfc) and the $\boldsymbol{g}$ tensor contain an abundant amount of information regarding the geometry and electronic structure of the system containing the unpaired electron. The hfc for a specific nucleus gives information on the chemical environment, based on the spin-density distribution and structure of the unpaired electron. The $\boldsymbol{g}$ tensor is dependent on the spin distribution of the whole radical. The variation in $\boldsymbol{g}$ from the free electron value ( $g=2.002319)$ is directly related to intermolecular interactions, providing local information on the nature of the unpaired electron(s). CW EPR spectroscopy was performed to monitor the presence of any radical species that could indicate that chain scission mechanisms were also occurring during irradiation. CW EPR spectra were collected from samples of DC745 that had been exposed to gamma radiation at doses of 12.5, 50 and $200 \mathrm{kGy}$ and a control sample that had not been exposed to gamma irradiation. Low temperature spectra collected at $77 \mathrm{~K}$ are shown in Figure 11. At a temperature of $77 \mathrm{~K}$ and a power of $5 \mathrm{~mW}$ there is a complex feature that dominates the spectrum and increases in intensity with increased radiation exposure, suggesting higher doses of gamma irradiation promote advanced degradation. The axial feature is centered near $g=2.013$ split by approximately $20-23$ hyperfine lines with spacings that vary from $2-6 \mathrm{G}$. The total signal spans $\sim 140 \mathrm{G}$.

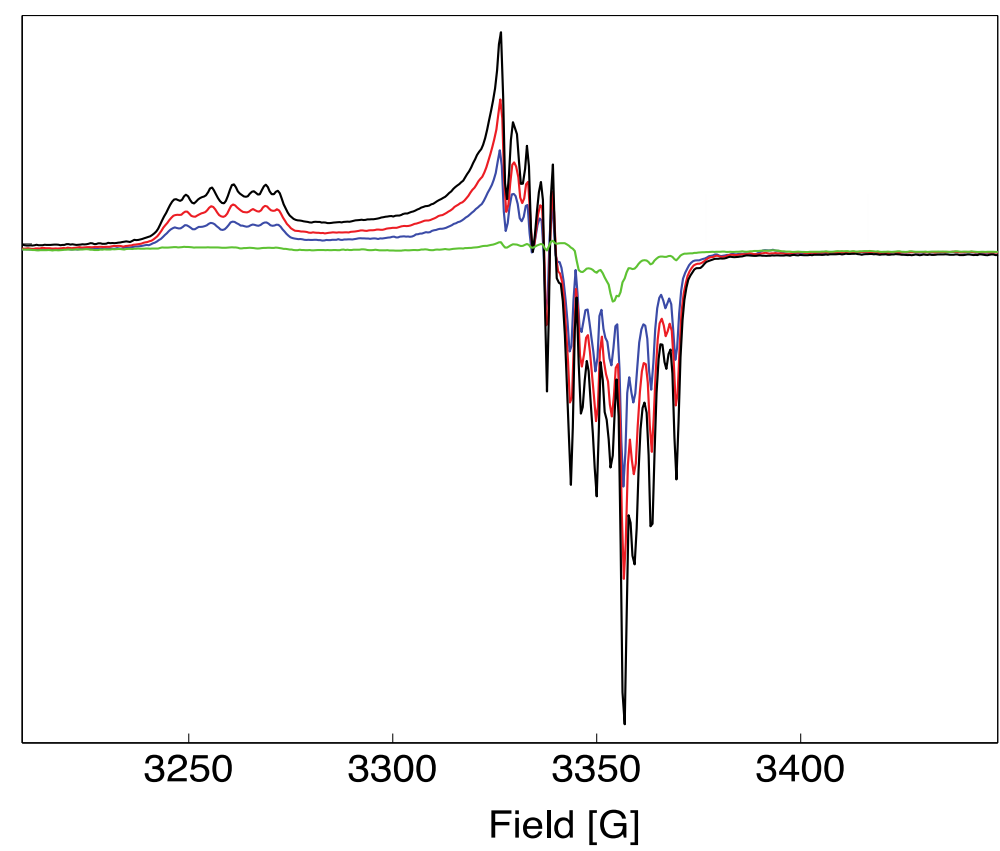


Figure 11. X-band (9.3985 GHz) CW EPR spectra of DC745 collected at a temperature of $77 \mathrm{~K}$. The green trace is the control sample; the remaining spectra are from samples irradiated to doses of $12.5 \mathrm{kGy}$ (blue trace), $50 \mathrm{kGy}$ (red trace), and $200 \mathrm{kGy}$ (black trace).

At low power there is a new signal at $g=2.002$ that dominates the spectrum, however, this signal is much more narrow spanning only $8 \mathrm{G}$. This signal is also present at room temperature and increases in intensity with higher gamma irradiation dose, as shown in Figure 12. While the control sample reveals a similar peak, the signal intensity is much lower. Due to the narrow nature of the signal and its presence at low powers it can likely be assigned to an organic radical. Furthermore, since the EPR spectra were collected months after the irradiation with no change in signal intensity; it is clear that this signal comes from a stable species. These initial results might suggest that these two radical species are forming due to reactions in which the polymer randomly cleaves during scission mechanisms.

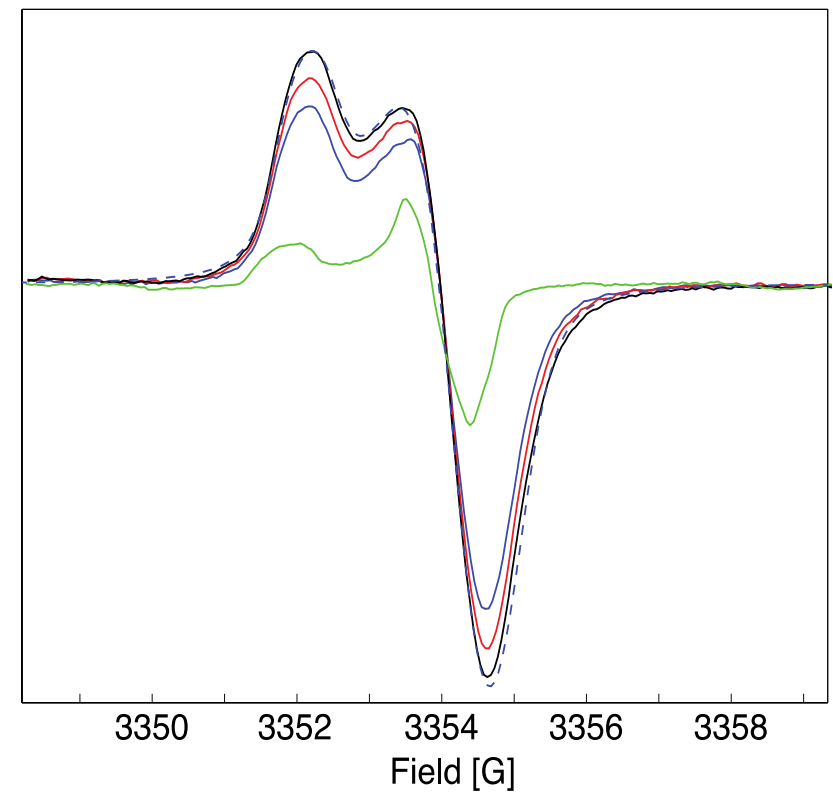

Figure 12. X-band (9.3985 GHz) CW EPR spectra of DC745 collected at a temperature of $77 \mathrm{~K}$. The green trace is the control sample, the blue, red and black trace are spectra from samples irradiated at doses of 12.5, 50, $200 \mathrm{kGy}$, respectively, (black trace) from 
samples irradiated to doses of $12.5 \mathrm{kGy}$. The simulation parameters are detailed in the text.

However, spectra collected from the exposed silica filler that had been isolated from the polymer suggest otherwise. The filler was irradiated to a dose of $100 \mathrm{kGy}$ in air, similar to the other DC745 samples. While there may be some residues of the polymer remaining in the silicon oxide filler, the EPR signals from the irradiated filler are nearly five times more intense than the sample of DC745 that was irradiated to a dose of $200 \mathrm{kGy}$ (see Figure 2 in the Supporting Information). This suggests that the origins of the EPR signals are primarily found within the filler matrix. The silica filler found within DC745 has significant amounts of quartz, and results obtained in the present work by XRF reveal the presence of relatively large amounts of aluminum in the resin $(2.04 \% \mathrm{Al}$, as well as 0.154\% Ca, 0.0355 Ti, 0.027 K, 0.016\% Fe, 0.008\% Ce). Previous studies have also shown that gamma irradiation of quartz leads to an aluminum hole paramagnetic center $\left[\mathrm{AlO}_{4}\right]^{0} .^{32-35}$ This paramagnetic species is explained by a defect such as an oxygen atom that has had an electron removed due to ionizing radiation, which is coupled to an aluminum ion that has been substituted for a silicon ion. ${ }^{36}$ While the majority of the unpaired spin density resides on the oxygen atom the dipolar hyperfine coupling is still strong enough to be observed in the CW EPR spectrum. In fact, the complexity of the spectrum can be accounted for the hyperfine interaction of the unpaired electron spin with a ${ }^{27} \mathrm{Al}$ nucleus, which has a nuclear spin $I=5 / 2$. Simulations of the spectrum reveal $g$-values of $g_{\|}=2.0615$ and $g \perp=2.0026$. These $g$-values are in good agreement with literature values. ${ }^{33,34}$

The narrow signal that persists at room temperature exhibits a typical structure of a point defect that has been previously observed in amorphous $\mathrm{SiO}_{2} \cdot{ }^{32,37}$ The magnitude of the signal intensity in the irradiated filler compared to the irradiated polymer confirms that the paramagnetic species also originates from the filler (see Figure 3 in the Supporting Information). A number of silica-based defects can form within materials such as the fumed silica and quartz found within the filler of DC745, especially, in the presence of oxygen. These paramagnetically active species include oxyradicals, which contain an oxygen-dangling bond ( $\mathrm{Si}-\mathrm{O} \cdot)$, otherwise known as a "non-bridging oxygen 
hole center" (NBOHC) and peroxy radicals ( $\mathrm{Si}-\mathrm{OO} \cdot)$. It can be difficult to distinguish between the two types of point defects, but for both species spin density distribution in the p-orbitals causes $g$-factor anisotropy, with the value of $g_{\|}$being much larger than $g \perp$. This is due to the large spin-orbit coupling constant of the oxygen atom and the small energy difference of the $2 p(\square)$ orbitals, one of which contains an unpaired electron. The $g$-values reported for NBOHC and peroxy species match well to those determined for the signal we observe. ${ }^{37-39}$ However, it is uncommon to see the signal of NBOHC species persist at room temperature. ${ }^{37}$ Conversely, peroxy radicals have been observed to be relatively temperature independent when in a rigid matrix. ${ }^{40}$ For the narrow signal we detect there is no distinct dependence upon temperature. Not only does this suggest that the radical species is most likely a peroxy species, but also suggests the radical is in a rigid matrix that does not allow for enough motion of freedom to average out the $g$-value anisotropy at room temperature. ${ }^{41}$ This result seems to indicate the presence of long-lived peroxide species. This signal could be simulated using a $g$-value of $g=[2.0016,2.0019$, $2.0031]$, a $g$-strain $=[0.0003,0.0004,0.0000]$ and Lorentzian linewidth of $0.0050 \mathrm{G}$.

\subsection{Changes in Mechanical Properties.}

To evaluate any changes in the mechanical properties of the post irradiated samples, compression tests were performed between crystallization and melting temperatures. The results of the compression experiments are shown in Figure 13. These plots reveal that the crystallization temperature decreases with increasing radiation dose. The control sample shows the highest stiffness for the temperatures tested. It also shows a propensity to maintain its deformed shape during the first loading cycle with very little viscoelastic recovery observed. Samples irradiated at doses of 12.5 and $50 \mathrm{kGy}$ reveal lower stiffness with nearly full viscoelastic recovery at a temperature of $-50{ }^{\circ} \mathrm{C}$. For the sample exposed at a dose of $12.5 \mathrm{kGy}$ only a gradual increase in the retained deformation was observed at a temperature of $-52{ }^{\circ} \mathrm{C}$. The sample irradiated at a dose of $200 \mathrm{kGy}$ displays the lowest stiffness, pure viscoelastic response near the crystallization temperature and the greatest decrease in the crystallization temperature (Figure 13e). This indicates that the overall crystallinity of the material decreases significantly with higher doses of radiation. This 
would be consistent with increased crosslinking yields under evolving inert conditions at the later stage of degradation beyond $100 \mathrm{kGy}$.
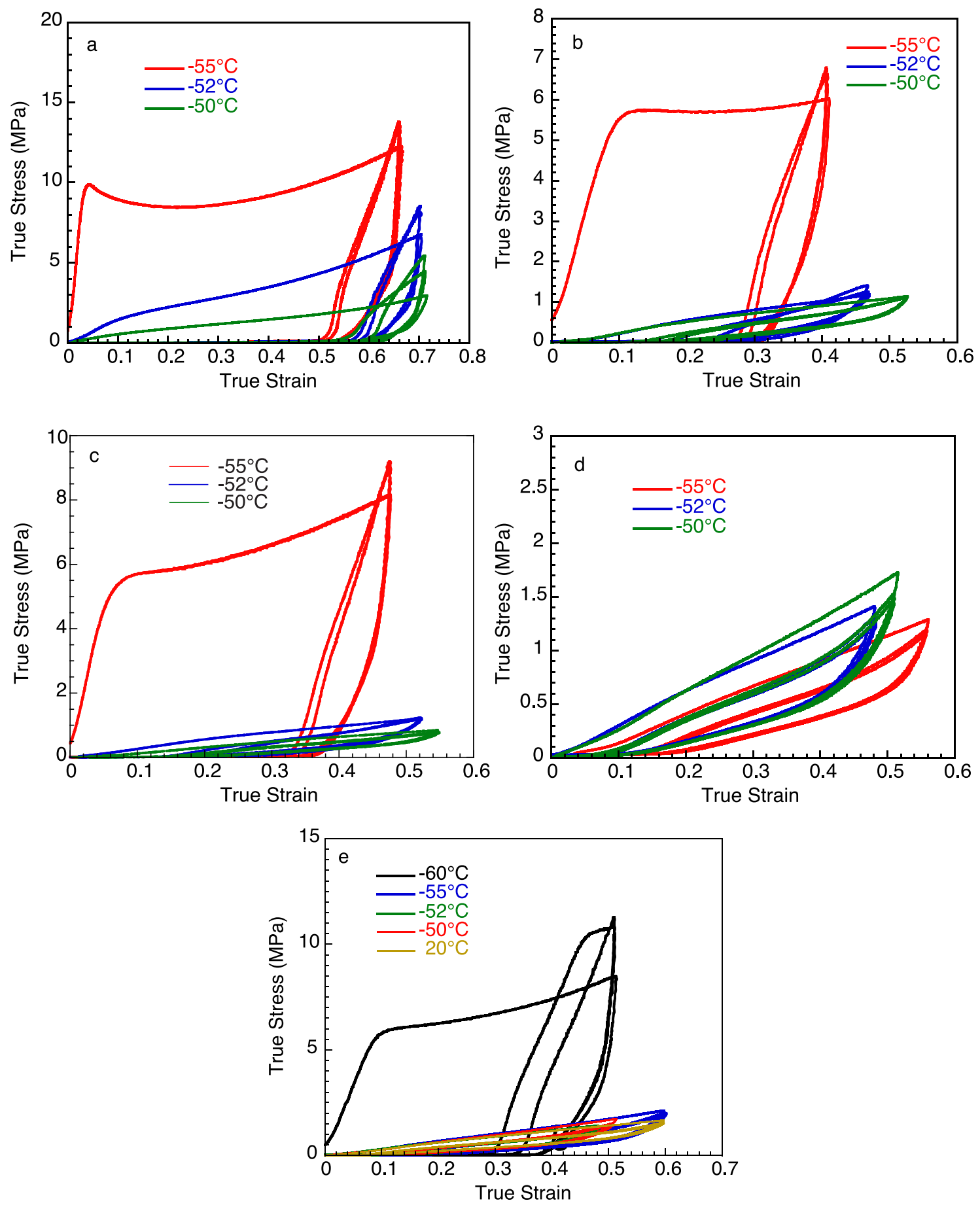
Figure 13. True Stress-True Strain plots of the DC745 material response near the phase transition temperature. Each plot shows three cycles of loading at test temperatures near the transition temperature. All of the samples were allow equilibrating at the test temperature for 1 hour and the strain was applied at $0.01 /$ second. The different plots are for the different radiation doses examined: a) control, b) 12.5, c) 50, d) $200 \mathrm{kGy}$ and e) $200 \mathrm{kGy}$ at additional temperatures of $20{ }^{\circ} \mathrm{C}$ and $-60{ }^{\circ} \mathrm{C}$.

While the control sample retains its compressed dimensions between the unloading and reloading cycles, the irradiated material displays near fully recovered dimension that are comparable to the uncompressed sample. This behavior suggests that the radiation exposure may have also slowed the kinetics of the phase transition (see Figure 14).
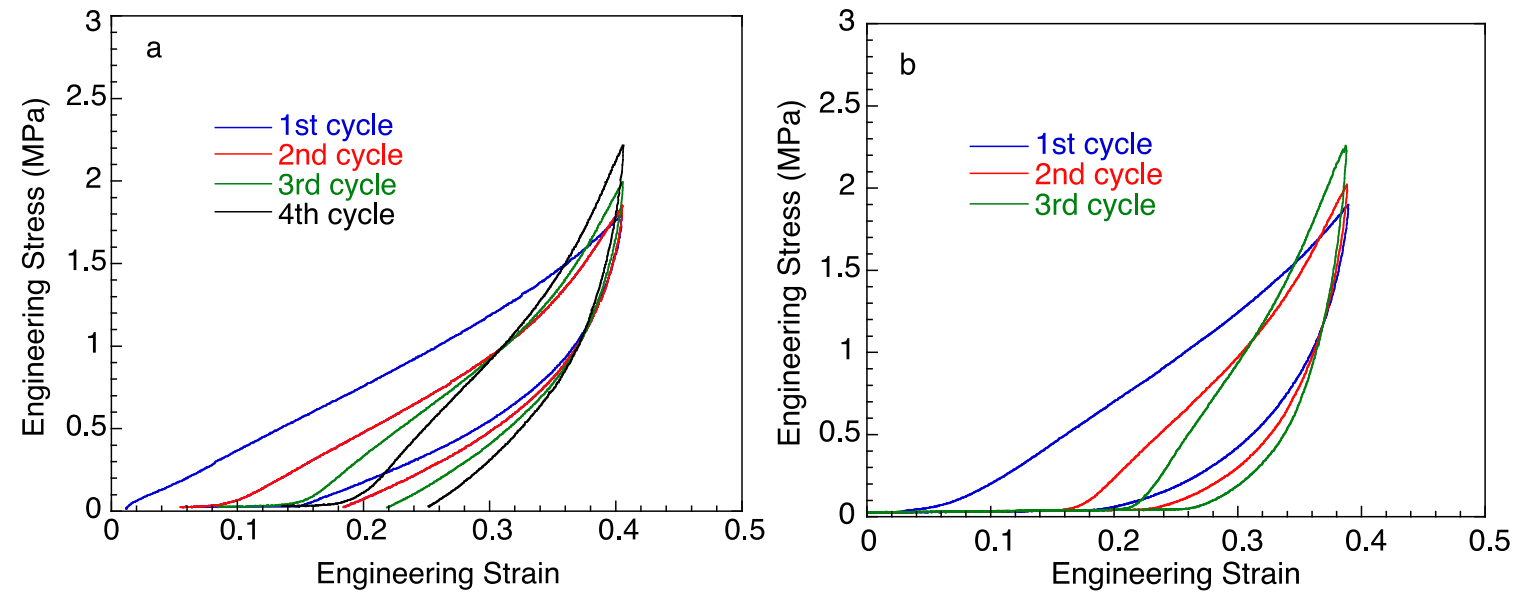

Figure 14. Engineering stress-engineering strain response showing the changing kinetic response between the control sample and the DC745 samples exposed to a dose of 12.5 $\mathrm{kGy}$. The strain was applied at $0.01 /$ second. a) At a temperature of $-50{ }^{\circ} \mathrm{C}$, with a dwell time of $\sim 10$ minutes; b) at a temperature of $-52{ }^{\circ} \mathrm{C}$, with a dwell time $\sim 1$ hour, at temperature respectively.

The stress-strain temperature dependent experiments measure the compressive loading response of the material, which is defined by the stiffness of the material. The 
results of these experiments are shown in Figure 15. At doses of 12.5 and $50 \mathrm{kGy}$ the stiffness of the materials decreases, but after a radiation dose of $200 \mathrm{kGy}$ the material begins to stiffen to a level similar to the control sample. This is peculiar since the material irradiated at a dose of $200 \mathrm{kGy}$ also shows the most decrease in the strength as a function of temperature, but may be consistent with the change to dominant inert conditions at the later stage of degradation beyond $100 \mathrm{kGy}$. Clearly, there is a complex relationship between increasing crosslink formation and decreasing crystallinity, which influences the strength of the polymer.
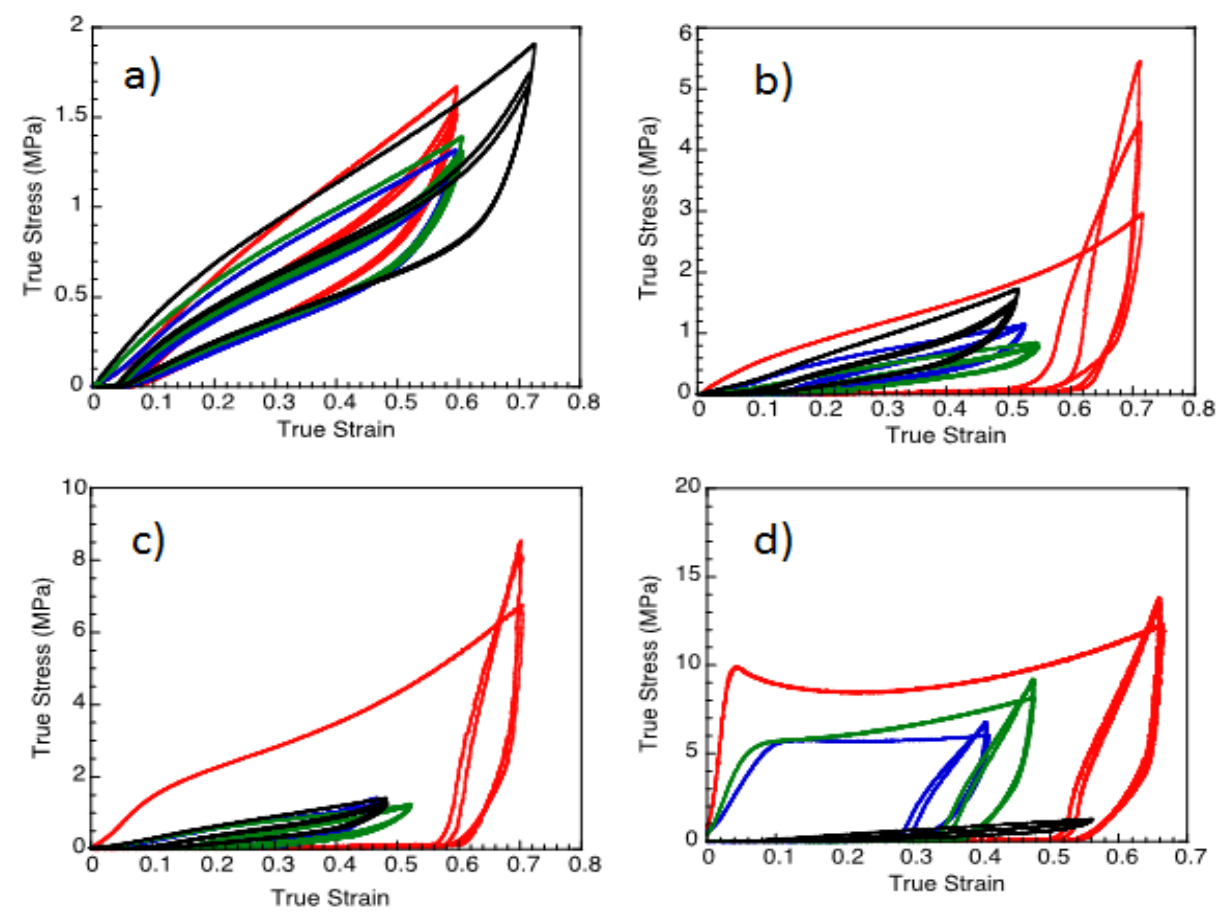

Figure 15. True Stress-True Strain plots illustrating the effect of radiation damage as a function of temperature. All samples were allowed to dwell at temperature for one hour before testing. The temperatures at which the data were collected were as follows: a) 20 ${ }^{\circ} \mathrm{C}$, b) $-50{ }^{\circ} \mathrm{C}$, c) $-52{ }^{\circ} \mathrm{C}$ and d) $-55^{\circ} \mathrm{C}$. (The green trace is the control sample, the blue trace is the spectra of the polymer that has been irradiated to $12.5 \mathrm{kGy}$, the red trace is irradiated to $50 \mathrm{kGy}$, and the black trace is the sample irradiated to $200 \mathrm{kGy}$ ). 
A more in depth evaluation of the room temperature experiments monitoring the stiffness as a function of strain are presented in Figure 16. The measurement of stiffness was taken as the slope of the stress-strain response from zero strain to the measured strain (secant modulus). After one cycle the $200 \mathrm{kGy}$ and the control sample were the stiffest materials, the samples exposed at 50 and $12.5 \mathrm{kGy}$ were moderately less stiff. Overall, the control sample had the greatest loss in stiffness as the strain is increased. The second plot shows the results for a third cycle, which is important to verify the "Mullin's" effect. The Mullin's" effect is associated with the reduction in stiffness due to damage or initial realignment of the polymeric structure. ${ }^{42}$ Nonetheless, the trends observed in the third cycle are similar to the first cycle. The only difference is observed is for the sample exposed at a dose of $200 \mathrm{kGy}$, which displays slightly more stiffness than the other three materials (Figure 16b). This difference is presumed to result from the greater crosslinking density that was observed by other techniques in this work and is again consistent with the transition to higher crosslink yields under inert atmosphere conditions. It should be noted that the final strain values reported for the $200 \mathrm{kGy}$ dose were also near the strain limits of the instrument. It is possible that the material will begin to stiffen even more at higher strain levels.
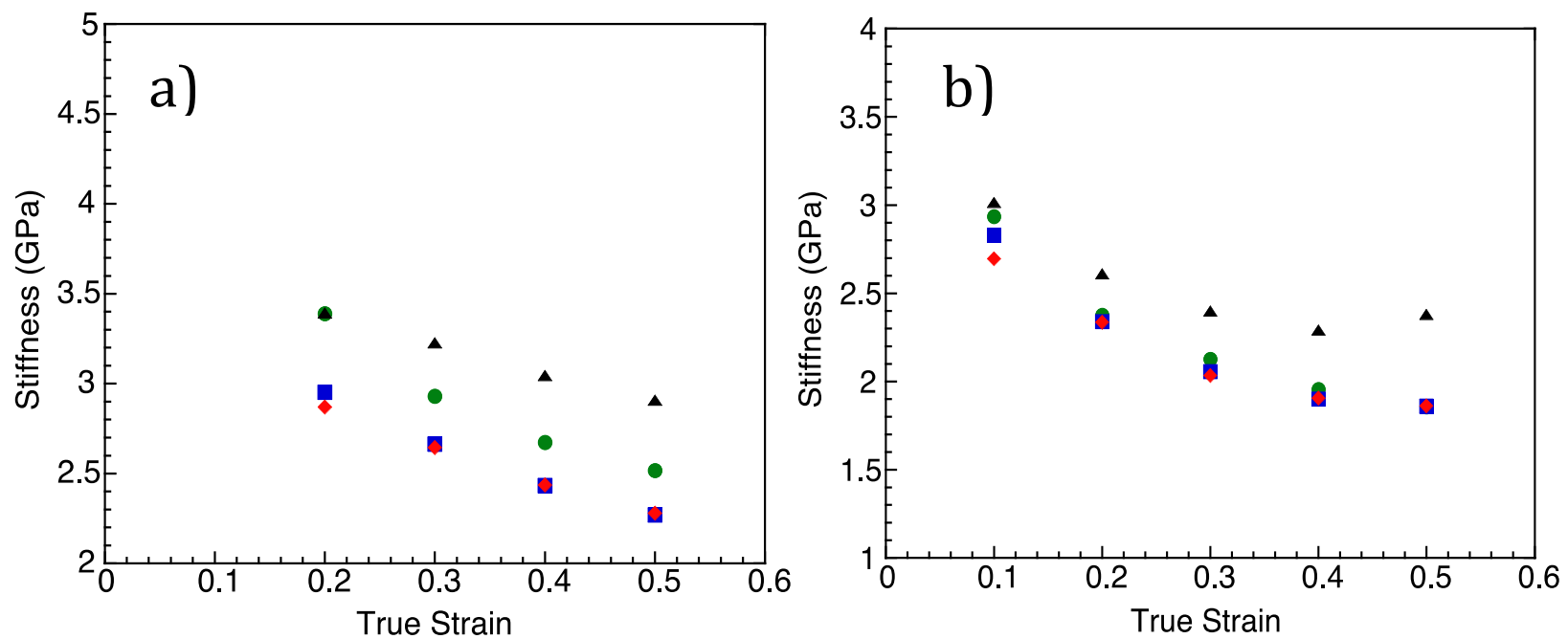

Figure 16. Stiffness versus strain for the various doses after a) one cycle of strain and b) three cycles of strain. Strain was applied at a temperature of $20{ }^{\circ} \mathrm{C}$, at a strain rate of $0.01 /$ second. (The green trace is the control sample, the blue trace is the spectra of the 
polymer that has been irradiated to $12.5 \mathrm{kGy}$, the red trace is irradiated to $50 \mathrm{kGy}$, and the black trace is irradiated to $200 \mathrm{kGy}$ ).

The results of the mechanical testing suggest there are competing mechanisms that are both stiffening and softening the polymer with increased radiation doses, which of course is convoluted by initially oxidative and later inert radiation chemistry for the 200 kGy material. The overall yield strength and the plateau observed in the mechanical testing near crystallization temperature indicate that the crystallization temperature is decreasing as a function of dose and non-oxidative processes. The results of the mechanical testing also suggest that radiation exposure slows the kinetic response to mechanical loading at low temperatures. Based on the experiments presented in this work it is clear that the crystallinity decreases with increased radiation dose. This reduction in crystallinity is counteracted by the increase in the cross-linking density, which causes the polymer chains to resist deformation and realignment during loading. This results in the material being stiffer and stronger.

\section{Conclusions.}

In the present work, a filled siloxane composite (DC745) was exposed to moderate gamma irradiation doses in air which changed for the highest dose to inert conditions during exposure. It is common to observe competing rates of chain scission and crosslinking in irradiated polymers under these conditions. Furthermore, due to the high permeability of oxygen in PDMS, oxidative scission was expected to play a role in gamma-irradiation induced aging. Our results demonstrate that DC745 is susceptible to radiation oxidative degradation under these aging conditions, which results in significant material property changes. Detailed characterization of irradiated samples provided insights on the radiolysis mechanisms and an understanding of the role of radiolysis in siloxane-based materials. Chemical changes induced by radiolysis resulted in an increase in cross-linking density, improvement of the thermal stability, decrease in crystallinity and melting temperature, decrease in solvent swelling, and finally stiffening of the material. At the same time, the presence of long-lived radicals was also detected. These 
radicals were assigned to defects in the filler that were induced from the gamma irradiation exposure. Additional crosslinking is more pronounced under inert than under oxidative conditions.

\section{Acknowledgments}

We thank Don Hanson and Maryla Wasiolek from Sandia National Laboratories for their help with experiments performed at the GIF. This work was funded by the Enhanced Surveillance Campaign, and the US Department of Energy's National Nuclear Security Administration under contract DE-AC52-06NA25396. 


\section{References.}

(1) Charlesby, A.; Garratt, P. G. Proc R Soc Lon Ser-A- 1963, 273, 117.

(2) Ormerod, M. G.; Charlesby, A. Polymer 1963, 4, 459.

(3) Maxwell, R. S.; Chinn, S. C.; Solyom, D.; Cohenour, R. Macromolecules 2005, 38, 7026 .

(4) Chinn, S. C.; Cook-Tendulkar, A.; Maxwell, R.; Wheeler, H.; Wilson, M.; Xie, Z. H. Polym Test 2007, 26, 1015.

(5) Herberg, J. L.; Chinn, S. C.; Sawvel, A. M.; Gjersing, E.; Maxwell, R. S. Polym Degrad Stab 2006, 91, 1701.

(6) Satti, A. J.; Andreucetti, N. A.; Ressia, J. A.; Vallat, M. F.; Sarmoria, C.; Valles, E. M. Eur Polym J 2008, 44, 1548.

(7) Menhofer, H.; Zluticky, J.; Heusinger, H. Rad Phys Chem 1989, 33, 561.

(8) Camino, G.; Lomakin, S. M.; Lazzari, M. Polymer 2001, 42, 2395.

(9) Flynn, J. H.; Wall, L. A. J Res Nbs a Phys Ch 1966, A 70, 487.

(10) Flynn, J. H.; Wall, L. A. J Polym Sci Pol Lett 1966, 4, 323.

(11) Stoll, S.; Britt, R. D. Phys Chem Chem Phys 2009, 11, 6614.

(12) Stoll, S.; Schweiger, A. J Magn Reson 2006, 178, 42.

(13) Vondracek, P.; Schatz, M. J Appl Polym Sci 1979, 23, 2681.

(14) Flory, P. J.; Rehner, J. J Chem Phys 1943, 11, 512.

(15) Flory, P. J.; Rehner, J. J Chem Phys 1943, 11, 521.

(16) Bueche, A. M. J Polym Sci 1955, 15, 97.

(17) Celina, M.; Gillen, K. T. Macromolecules 2005, 38, 2754.

(18) Celina, M. C. Polym Degrad Stab 2013, 98, 2419.

(19) Wise, J.; Gillen, K. T.; Clough, R. L. Rad Phys Chem 1997, 49, 565.

(20) Gillen, K. T.; Clough, R. L. Polymer 1992, 33, 4358.

(21) Wise, J.; Gillen, K. T.; Clough, R. L. Polym Degrad Stab 1995, 49, 403.

(22) Celina, M. C.; Dayile, A. R.; Quintana, A. Polymer 2013, 54, 3290.

(23) Rost, H.; Bleier, A.; Becker, W. In Operability of nuclear systems in normal and adverse environments. Volume 21989.

(24) Stern, S. A.; Shah, V. M.; Hardy, B. J. J Polym Sci Pol Phys 1987, 25, 1263.

(25) Clough, R. L. Nucl Instrum Methods Phys R Sect-B 2001, 185, 8.

(26) Roland, C. M.; Aronson, C. A. Polym Bull 2000, 45, 439.

(27) Aranguren, M. I. Polymer 1998, 39, 4897.

(28) Mayer, B. P.; Lewicki, J. P.; Chinn, S. C.; Overturf, G. E.; Maxwell, R. S. Polym Degrad Stab 2012, 97, 1151.

(29) Flory, P. J. J Chem Phys 1950, 18, 108.

(30) Maxwell, R. S.; Balazs, B. J Chem Phys 2002, 116, 10492.

(31) Hill, D. J. T.; Preston, C. M. L.; Whittaker, A. K.; Hunt, S. M. Macromol Symp 2000, 156, 95.

(32) Eaton, G. R.; Eaton, S. S.; Quine, R. W.; Mitchell, D.; Kathirvelu, V.; Weber, R. T. J Magn Reson 2010, 205, 109.

(33) Dobosz, B.; Krzyminiewski, R. Appl Radiat Isotopes 2007, 65, 392.

(34) Dobosz, B.; Krzyminiewski, R. Radiat Meas 2007, 42, 213.

(35) Botis, S. M.; Pan, Y. M. Phys Chem Miner 2010, 37, 119.

(36) Obrien, M. C. M. Proc R Soc Lon Ser-A 1955, 231, 404. 
(37) Skuja, L.; Kajihara, K.; Hirano, M.; Hosono, H. Nucl Instrum Methods Phys R Sect-B 2012, 286, 159.

(38) Kadono, K.; Itakura, N.; Akai, T.; Yamashita, M.; Yazawa, T. J Non-Cryst Solids 2010, 356, 232.

(39) Takemoto, J.; Moritani, K.; Takagi, I.; Akiyoshi, M.; Moriyama, H. J Nucl Mater 2008, 374, 293.

(40) Rånby, B. G. ESR spectroscopy in polymer research; Berlin: SpringerVerlag, New York: Springer-Verlag, 1977.

(41) Hori, Y.; Makino, Y.; Kashiwabara, H. Polymer 1984, 25, 1436.

(42) Diani, J.; Fayolle, B.; Gilormini, P. Eur Polym J 2009, 45, 601. 